\title{
Haematopoietic SCT in severe autoimmune diseases: updated guidelines of the European Group for Blood and Marrow Transplantation
}

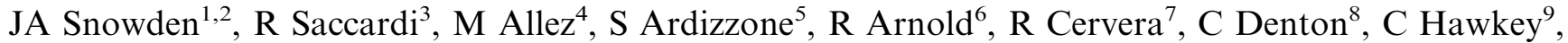 \\ M Labopin ${ }^{10}$, G Mancardi ${ }^{11}$, R Martin ${ }^{12}$, JJ Moore ${ }^{13,20}$, J Passweg ${ }^{14}$, C Peters ${ }^{15,21}$, M Rabusin ${ }^{16,21}$, \\ M Rovira ${ }^{17}$, JM van Laar $^{18}$ and D Farge ${ }^{19}$, on behalf of the EBMT Autoimmune Disease Working Party \\ (ADWP) and Paediatric Diseases Working Party (PDWP)
}

\begin{abstract}
${ }^{1}$ Department of Haematology, Sheffield Teaching Hospitals NHS Trust, Sheffield, UK; ${ }^{2}$ Department of Oncology, University of Sheffield, Sheffield, UK; ${ }^{3}$ Department of Haematology, Careggi University Hospital, Firenze, Italy; ${ }^{4}$ Service de Gastroentérologie, INSERM U 662, Hôpital St Louis, Paris, France; ${ }^{5}$ Department of Gastroenterology, Sacco University Hospital, Milan, Italy; ${ }^{6}$ Charite Hospital Berlin, Berlin, Germany; ${ }^{7}$ Department of Autoimmune Diseases, Hospital Clinic, Barcelona, Spain; ${ }^{8}$ Centre for Rheumatology, Royal Free and University College Medical School, Hampstead, London, UK; ${ }^{9}$ Nottingham Digestive Diseases Centre, University of Nottingham, Nottingham, UK, ${ }^{10}$ Hôpital Saint Antoine, Service d'Hématologie et Thérapie Cellulaire, AP-HP, UPMC Univ Paris 06, Paris, France; ${ }^{11}$ Department of Neuroscience, Ophthalmology and Genetics, University of Genova, Genova, Italy; ${ }^{12}$ Institute for Neuroimmunology and Clinical MS Research, Hamburg, Germany; ${ }^{13}$ St Vincent's Hospital, Sydney, NSW, Australia; ${ }^{14}$ Universitaetsspital Basel, Basel, Switzerland; ${ }^{15}$ BMT Unit, St Anna Children's Hospital, Vienna, Austria; ${ }^{16}$ BMT Unit, Department of Pediatrics, Institute of Maternal and Child Health Burlo Garofolo, Trieste, Italy; ${ }^{17}$ SCT Unit, Hematology Department, Hospital Clinic, Barcelona, Spain; ${ }^{18}$ Newcastle University, Newcastle-Upon-Tyne, UK and ${ }^{19}$ Department of Internal Medicine, INSERM U 796, Hôpital St Louis, Paris, France
\end{abstract}

In 1997, the first consensus guidelines for haematopoietic SCT (HSCT) in autoimmune diseases (ADs) were published, while an international coordinated clinical programme was launched. These guidelines provided broad principles for the field over the following decade and were accompanied by comprehensive data collection in the European Group for Blood and Marrow Transplantation (EBMT) AD Registry. Subsequently, retrospective analyses and prospective phase I/II studies generated evidence to support the feasibility, safety and efficacy of HSCT in several types of severe, treatment-resistant ADs, which became the basis for larger-scale phase II and III studies. In parallel, there has also been an era of immense progress in biological therapy in ADs. The aim of this document is to provide revised and updated guidelines for both the current application and future development of HSCT in ADs in relation to the benefits, risks and health economic considerations of other modern treatments. Patient safety considerations are central to guidance on patient selection

Correspondence: Dr JA Snowden, Department of Haematology, Sheffield Teaching Hospitals NHS Trust, University of Sheffield, Glossop Road, Sheffield S10 2JF, UK.

E-mail: john.snowden@sth.nhs.uk or Professor D Farge, EBMT Autoimmune Diseases Working Party (ADWP), EBMT Paris Office, Paris, France.

E-mail: dominique.farge-bancel@sls.aphp.fr

${ }^{20}$ Representative of the Bone Marrow Transplantation Society of Australia and New Zealand (BMTSANZ).

${ }^{21}$ Representative of the EBMT Paediatric Diseases Working Party (PDWP).

Received 3 May 2011; revised and accepted 4 July 2011; published online 17 October 2011 and HSCT procedural aspects within appropriately experienced and Joint Accreditation Committee of International Society for Cellular Therapy and EBMT accredited centres. A need for prospective interventional and non-interventional studies, where feasible, along with systematic data reporting, in accordance with EBMT policies and procedures, is emphasized.

Bone Marrow Transplantation (2012) 47, 770-790; doi:10.1038/bmt.2011.185; published online 17 October 2011 Keywords: haematopoietic SCT; autoimmune diseases; autologous; allogeneic; guidelines; recommendations

\section{Introduction}

\section{Background}

Autoimmune diseases (ADs) are heterogeneous both in manifestation and severity. Immunosuppressive therapy, including novel biological therapies, enables short-term disease control and minimization of organ damage in most cases, but long-term treatment-free remission and/or definitive cure remain elusive. Major organ involvement, rapidly progressing disease and persistent disease activity result in significant disability, reduction in quality of life (QoL) and life expectancy. Toxicities of chronic treatment and the personal and societal costs are considerable. In this context, haematopoietic SCT (HSCT) has been used in severe AD for the past 15 years to control otherwise resistant disease activity, or even cure, by inducing fundamental immunological changes never previously seen with other forms of therapy. 
The concept of HSCT in severe ADs initially evolved in animal models, ${ }^{1-7}$ with the potential benefits in humans supported by reports of profound clinical response of ADs to HSCT performed for other conventional indications. ${ }^{8,9}$ From 1995, the first HSCT procedures specifically for ADs were performed, and, in 1996, the European Group for Blood and Marrow Transplantation (EBMT) AD Working Party (ADWP) was launched. ${ }^{10,11}$ The collaboration was progressively built on by active involvement with specialist European societies working together with the EBMT, specifically the European League against Rheumatism and its working groups in Systemic Sclerosis (EUSTAR) and Lupus Erythematosus (Eurolupus), the European Crohn's and Colitis Organization, and the European Committee for Treatment and Research in Multiple Sclerosis. Further interactions outside of Europe involved the Center for International Bone Marrow Transplant Registry $^{12}$ and the National Institutes of Health, ${ }^{12,13}$ along with large HSCT programmes in the field, such as Northwestern University, Chicago, and active groups in Australia, Brazil and China.

A database dedicated to adult and paediatric patients with AD treated with high-dose chemotherapy and autologous, syngeneic or allogeneic HSCT was created and EBMT centres were requested to report all procedures with annual updates. Thereafter, specific data forms were introduced into the Central EBMT database (http:// www.ebmt.org/4Registry/registry3.html). It is currently estimated that around 3000 AD patients have now been treated worldwide by HSCT. Table 1 summarizes the current EBMT AD Registry as of June 2011 in terms of AD indications in the adult $(\geqslant 18$ years) and paediatric $(<18$ years) age groups. The majority of adult patients have been treated with autologous HSCT $(n=1090)$, with donor HSCT $(n=25)$ comprised of related donor HSCT $(n=20$, including two syngeneic HSCT) and unrelated donor HSCT $(n=5)$. Likewise most paediatric patients also underwent autologous HSCT $(n=119)$, although donor HSCT was proportionally more frequent $(n=40)$, with related donor HSCT $(n=24$, including two syngeneic HSCT) and unrelated donor HSCT $(n=16)$. The remainder of worldwide cases have been reported to the United Statesbased CIBMTR, or have been performed in Asia or the Eastern Mediterranean regions, or are present in other individual centre registries outside of Europe, such as Northwestern University, Chicago. ${ }^{12,14-16}$

Successive analyses of the EBMT database provided evidence for the feasibility and the toxicity of the HSCT procedures across a large number of ADs. ${ }^{17,18}$ Prospective phase I/II studies were progressively reported across a wide range of $\mathrm{AD}$, including multiple sclerosis (MS), ${ }^{19-27}$ systemic sclerosis (SSc), ${ }^{28-31}$ systemic lupus erythematosus (SLE), ${ }^{14}$ rheumatoid arthritis (RA), ${ }^{32-34}$ juvenile chronic arthritis (JIA), ${ }^{35-37}$ Crohn's disease (CD) ${ }^{38-40}$ and type 1 diabetes (T1D). ${ }^{41-43}$ In the most recent general retrospective analysis, among 900 patients undergoing first autologous HSCT, the overall 5-year survival was $85 \%$, with $43 \%$ PFS. Outcomes varied with diagnosis, age and centre activity. ${ }^{18}$ Retrospective analysis of limited numbers of allogeneic HSCT, including the use of donor T-cell infusions, confirmed the ability to achieve very prolonged remission,
Table 1

EBMT database of autoimmune diseases, June 2011

\begin{tabular}{|c|c|c|c|}
\hline \multirow[t]{2}{*}{ Diseases } & \multicolumn{3}{|c|}{ No. of patients } \\
\hline & $\begin{array}{l}\text { Paediatrics }^{\mathrm{a}} \\
\text { Auto/Allo }\end{array}$ & $\begin{array}{c}\text { Adults } \\
\text { Auto } / \text { Allo }\end{array}$ & $\begin{array}{c}\text { Total } \\
\text { Auto/Allo }\end{array}$ \\
\hline Neurological diseases & $9 / 0$ & $493 / 4$ & $502 / 4$ \\
\hline Multiple sclerosis & $7 / 0$ & $462 / 3$ & $469 / 3$ \\
\hline $\begin{array}{l}\text { Other neurological diseases, } \\
\text { for example, myasthenia } \\
\text { gravis }\end{array}$ & $2 / 0$ & $31 / 1$ & $33 / 1$ \\
\hline Connective tissue diseases & $29 / 1$ & $367 / 1$ & $396 / 2$ \\
\hline Systemic sclerosis & $9 / 0$ & $257 / 0$ & $266 / 0$ \\
\hline Systemic lupus erythematosus & $17 / 1$ & $78 / 1$ & $95 / 2$ \\
\hline $\begin{array}{l}\text { Polymyositis- } \\
\text { dermatomyositis }\end{array}$ & 0 & $16 / 0$ & $16 / 0$ \\
\hline $\begin{array}{l}\text { Other connective tissue } \\
\text { disease, including Sjogren's } \\
\text { disease }\end{array}$ & $2 / 0$ & $16 / 0$ & $18 / 0$ \\
\hline Arthritis & $62 / 4$ & $90 / 2$ & $152 / 6$ \\
\hline Rheumatoid arthritis & $1 / 0$ & $75 / 2$ & $76 / 2$ \\
\hline Juvenile chronic arthritis & $61 / 3$ & $10 / 0$ & $71 / 3$ \\
\hline $\begin{array}{l}\text { Other arthritis, including } \\
\text { psoriatic }\end{array}$ & $0 / 1$ & $5 / 0$ & $5 / 1$ \\
\hline Vasculitis & $3 / 3$ & $26 / 1$ & $29 / 4$ \\
\hline Haematological & $7 / 21$ & $31 / 13$ & $38 / 34$ \\
\hline Immune thrombocytopenia & $3 / 1$ & $18 / 3$ & $21 / 4$ \\
\hline $\begin{array}{l}\text { Autoimmune haemolytic } \\
\text { anaemia }\end{array}$ & $1 / 3$ & $8 / 2$ & $9 / 5$ \\
\hline Evans' syndrome & $2 / 10$ & $3 / 2$ & $5 / 12$ \\
\hline $\begin{array}{l}\text { Other haematological, } \\
\text { including pure red/white cell } \\
\text { aplasia }\end{array}$ & $1 / 7$ & $2 / 6$ & $3 / 13$ \\
\hline Inflammatory bowel disease & $8 / 5$ & $51 / 1$ & $59 / 6$ \\
\hline Crohn's disease & $7 / 1$ & $49 / 0$ & $56 / 1$ \\
\hline Ulcerative colitis & $1 / 2$ & $1 / 0$ & $1 / 3$ \\
\hline Other & $0 / 2$ & $1 / 1$ & $1 / 3$ \\
\hline Type 1 diabetes & & $10 / 0$ & $10 / 0$ \\
\hline Others & $1 / 6$ & $22 / 2$ & $23 / 8$ \\
\hline Total & $119 / 40$ & $1090 / 24$ & $1209 / 64$ \\
\hline
\end{tabular}

Abbreviation: EBMT $=$ European Group for Blood and Marrow Transplantation.

${ }^{\text {aa }}$ Paediatric $=$ less than 18 years old at HSCT.

but with significantly more toxicity and TRM than with autologous HSCT ${ }^{44}$ Other retrospective analyses were used to support the feasibility, safety and efficacy in specific ADs, including MS, SSc, SLE, RA, JIA, autoimmune cytopenias, vasculitis and paediatric diseases. ${ }^{45-54}$

The results of retrospective and prospective studies were the basis for randomized phase II/III studies in the major disease indications: in SSc (ASTIS, http://www.astistrial. com; ASSIST, http:/www.clinicaltrials.gov; SCOT, http:// www.clinicaltrials.gov); in MS (ASTIMS, http://www. astims.org; MIST (Multiple Sclerosis International Stem cell Trial), http://www.clinicaltrials.gov); and in CD (ASTIC, http://www.nottingham.ac.uk/icr/astic/).

\section{Mechanism of action}

For many years, the use of HSCT to induce tolerance by replacing (allogeneic) or resetting (autologous) immune 
responses in patients with ADs by HSCT remained an attractive prospect, ${ }^{55}$ arising from genetically prone and immunized animal models of AD treated with allogeneic, syngeneic, autologous and pseudo-autologous HSCT. ${ }^{1-7}$ The preclinical evidence for a graft-vs-autoimmune effect important in the replacement of a dysfunctional immune system by allogeneic HSCT has been subsequently supported by clinical evidence. ${ }^{44,56-60}$

In autologous HSCT, analysis of the regenerating adaptive immune system showed normalization of the restricted $\mathrm{T}$-cell repertoire, with sustained shifts in $\mathrm{T}$ - and B-cell subpopulations from memory to naïve cell dominance, supportive of thymic reprocessing and re-education of the reconstituting immune system. ${ }^{61,62}$ In addition, restoration of normal or raised levels of CD4 + regulatory $\mathrm{T}$ cells with the disappearance of circulating plasmablasts is reported in $\mathrm{JIA},{ }^{63-65}$ and unusual $\mathrm{CD} 8+$ FoxP3 + regulatory T-cell subsets, capable of inhibiting the pathogenic Tcell response to autoepitopes in nucleosomes, are seen in SLE following autologous HSCT, but not after conventional immunosuppressive therapies. ${ }^{66,67}$ These results separated the nonspecific immunosuppressive changes, observed in both blood and tissue after cytotoxic therapy, ${ }^{62,68}$ from immune re-educative changes supporting immune tolerance. ${ }^{69}$ Other downstream changes, such as reduction in dermal fibrosis, ${ }^{29,70,71}$ with increased dermal microcirculation ${ }^{72,73}$ and early regression of the extent of CT scan fibrosis ${ }^{74}$ in systemic sclerosis were reported.

\section{Advances in biological therapies and other non-HSCT treatments}

The advent of many novel biological therapies improved outcomes in many ADs in recent years. Nonetheless, significant numbers of patients fail to respond or develop resistance to modern biological-based therapies or develop unacceptable side effects and severe infectious complications, long-term malignancies or secondary ADs. ${ }^{75-77}$ In addition, chronic administration of novel treatments is also a major socioeconomic challenge. There remains a need for highly active, but deliverable treatment regimens for patients with a poor prognosis due to rapidly progressive and treatment-resistant ADs.

\section{Guidelines' process and aims}

The first guidelines published in 1997 represented a relatively uniform approach toward developing the field both within and outside clinical trials, with an emphasis on registry reporting. ${ }^{11}$ Further brief, revised recommendations are included in various iterations of the general EBMT indications for HSCT. ${ }^{78}$ The aims of these current updated guidelines are to support HSCT centres running a local trial, or dealing with a complex AD patient, and also to guide health-care administrative bodies and insurance companies. There is an emphasis on patient safety, with criteria for selection and HSCT procedural aspects, underpinned by a requirement for accreditation of HSCT programmes by JACIE (Joint Accreditation Committee of International Society for Cellular Therapy and EBMT) or equivalent quality management systems, which improve clinical outcomes in HSCT. ${ }^{79,80}$ Where possible, inclusion of patients on prospective clinical studies, ideally randomized controlled trials, and also prospective noninterventional studies (in accordance with current EBMT registry guidelines) is also essential for development of the field.

Levels of evidence have been inserted according to the currently accepted EBMT grading system (Tables 2a and $b$ ). Each disease-specific panel session workshop reported at the EBMT- and National Institutes of Health-supported meeting in Florence, November 2009, ${ }^{13}$ was used as a source of consensus. Subsequently, the guidelines were formally discussed at two successive EBMT ADWP meetings in March and October 2010 and proposed recommendations circulated among active members before finalization in close interaction with the EBMT Paediatric Diseases Working Party and the Australasian Society for BMT.

Table 2 EBMT disease indications - (a) adults and (b) paediatrics

\begin{tabular}{|c|c|c|c|}
\hline Disease & $\begin{array}{l}\text { Sibling } \\
\text { donor }\end{array}$ & $\begin{array}{c}\text { Well-matched } \\
\text { unrelated }^{\mathrm{a}}\end{array}$ & Autologous \\
\hline \multicolumn{4}{|l|}{ (a) } \\
\hline MS & $\mathrm{D} / \mathrm{III}$ & GNR/III & $\mathrm{CO} / \mathrm{II}$ \\
\hline $\mathrm{SSc}$ & $\mathrm{D} / \mathrm{III}$ & GNR/III & $\mathrm{CO} / \mathrm{II}$ \\
\hline SLE & D/III & GNR/III & $\mathrm{CO} / \mathrm{II}$ \\
\hline Crohn's & GNR/III & GNR/III & $\mathrm{CO} / \mathrm{II}$ \\
\hline RA & GNR/III & GNR/III & $\mathrm{CO} / \mathrm{II}$ \\
\hline Vasculitis & GNR/III & GNR/III & $\mathrm{CO} / \mathrm{II}$ \\
\hline $\begin{array}{l}\text { Polymyositis- } \\
\text { dermatomyositis }\end{array}$ & GNR/III & GNR/III & $\mathrm{CO} / \mathrm{II}$ \\
\hline CIPD & GNR/III & GNR/III & $\mathrm{CO} / \mathrm{II}$ \\
\hline NMO & GNR/III & GNR/III & $\mathrm{CO} / \mathrm{II}$ \\
\hline Cytopenia & $\mathrm{CO} / \mathrm{II}$ & D/III & $\mathrm{CO} / \mathrm{II}$ \\
\hline T1D & GNR/III & GNR/III & $\mathrm{D} / \mathrm{III}$ \\
\hline RCD II & GNR/III & GNR/III & $\mathrm{D} / \mathrm{III}$ \\
\hline \multicolumn{4}{|l|}{ (b) } \\
\hline JIA & $\mathrm{D} / \mathrm{III}$ & GNR/III & $\mathrm{CO} / \mathrm{II}$ \\
\hline JSSc & $\mathrm{D} / \mathrm{III}$ & GNR/III & $\mathrm{CO} / \mathrm{II}$ \\
\hline JSLE & D/III & GNR/III & $\mathrm{CO} / \mathrm{II}$ \\
\hline Crohn’s & GNR/III & GNR/III & $\mathrm{CO} / \mathrm{II}$ \\
\hline Vasculitis & GNR/III & GNR/III & $\mathrm{CO} / \mathrm{II}$ \\
\hline $\begin{array}{l}\text { Polymyositis- } \\
\text { dermatomyositis }\end{array}$ & GNR/III & GNR/III & $\mathrm{CO} / \mathrm{II}$ \\
\hline Cytopenia & $\mathrm{CO} / \mathrm{II}$ & $\mathrm{CO} / \mathrm{II}$ & $\mathrm{CO} / \mathrm{II}$ \\
\hline T1D & GNR/III & GNR/III & $\mathrm{D} / \mathrm{III}$ \\
\hline
\end{tabular}

Abbreviations: CIPD = chronic inflammatory demyelinating polyradiculoneuropathy; EBMT = European Group for Blood and Marrow Transplantation; JIA = juvenile chronic arthritis; JSLE = juvenile systemic lupus erythematosus; JSSc = juvenile systemic sclerosis; $\mathrm{MS}=$ multiple sclerosis; $\mathrm{NMO}=$ neuromyelitis optica; $\mathrm{T} 1 \mathrm{D}=$ type 1 diabetes; $\mathrm{RA}=$ rheumatoid arthritis; RCD II = refractory type II coeliac disease; $\mathrm{SSc}=$ systemic sclerosis; SLE = systemic lupus erythematosus.

${ }^{a} \mathrm{~A}$ well-matched unrelated donor is defined as a $9 / 10$ or $10 / 10$ identical donor based on HLA high-resolution typing for class I (HLA-A, -B, -C) and II (HLA-DRB1, DQB1).

EBMT grades of evidence: ${ }^{78} \mathrm{I}=$ evidence from at least one well-executed randomized trial; $\mathrm{II}=$ evidence from at least one well-designed clinical trial without randomization: cohort or case-controlled analytical studies (preferably from more than one centre), multiple time-series studies: or dramatic results from uncontrolled experiments; III = evidence from opinions of respected authorities based on clinical experience, descriptive studies or reports from expert committee.

EBMT grades of recommendation: ${ }^{78} \mathrm{CO}=$ Clinical Option: can be carried out after careful assessment of risks and benefits; $\mathrm{D}=$ developmental; $\mathrm{GNR}=$ generally not recommended; $\mathrm{S}=$ standard: generally indicated in suitable patients. 


\section{General recommendations}

\section{Clinical practice}

Evidence for the feasibility, efficacy and toxicity of HSCT in various adult and paediatric ADs has been summarized in a large number of detailed reviews and registry analyses. ${ }^{14,17,18,81-87}$ The risks of toxicity and TRM vary between donor source, intensity of conditioning regimens and AD category, and the potential for safer yet equally effective non-HSCT treatments should be actively pursued in all cases, including modern biological therapies, where deliverable.

\section{Recommendations}

- HSCT should be considered as a therapeutic option at second line or beyond for patients with severe ADs progressing despite standard established and/or approved therapy (level II).

- In patients for whom HSCT represents a treatment option, referral should be made to a centre with appropriate inter-disciplinary interaction using combined haematological and AD specialist experience to select and manage AD patients. Such centres should have JACIE accreditation or equivalent (level II).

- Whenever possible, HSCT in AD should be performed in the context of a phase II or III clinical trial with welldefined end points and eligibility criteria in accordance with good clinical practice and appropriate regulatory requirements (level III).

- Approved prospective non-interventional studies may provide meaningful clinical data where full phase III randomized controlled trials are not feasible, and are the preferred option over 'ad hoc' procedures (level III).

- If no study or clinical trial is available, the patient should be considered under the EBMT category 'Clinical Option' (CO) after documented multidisciplinary meetings, clinical/research ethics committee review and/or external expert second opinions from both HSCT and relevant AD specialists. The alternative non-HSCT treatment options, including potential participation in other clinical trials, should be central to this assessment (level III).

- In addition to JACIE accreditation (or equivalent), centres should specifically train staff (physicians, nurses, data managers) in specific ADs (level III).

\section{Data reporting and biobanking}

The international HSCT registries are central to the development of HSCT to ADs. The EBMT database is the largest worldwide and unique MED-A and specific MED-B forms for MS, SSc, SLE, RA and CD can be downloaded at http://www.ebmt.org/4Registry/registry3. $\mathrm{html}$. Complete data registration has proven more challenging than 'routine', predominantly haematological, indications for HSCT since follow-up lies predominantly outside the specialty of haematology, data managers are generally less familiar with $\mathrm{AD}$, and, in the long term, many patients are seen in departments outside the transplant centre.

HSCT provides a unique opportunity to collect adequate serum, plasma and cell samples in addition to biological samples according to each AD category and organ involvement at baseline, during the immunosuppressionfree remission, and at potential relapse for both and pathogenetic and mechanistic studies. Local or central biobanking, within regulatory requirements, is essential.

\section{Recommendations}

- Long-term formalized follow-up and data reporting of all AD patients after HSCT to registries are a minimum recommendation. EBMT MED A (or equivalent) and disease-specific MED B (or equivalent) data reporting are available for these purposes. Annual review and data reporting is recommended to capture all outcomes, including late effects of HSCT (level III).

- Centres performing HSCT for ADs should provide systems for long-term follow-up. Annual simultaneous follow-up consultation of the AD specialist and the HSCT specialist is recommended. If patients are discharged from the transplant centre for mid/long-term follow-up under the referring specialist, the contact details should be available to the registry (level III).

- Data managers should be adequately trained and supervised by relevant BMT and AD specialists (level III).

- Biobanking within current regulatory frameworks allowing to maximise the utility of stored biological samples should be actively sought (level III)

\section{Statistical aspects}

The number and heterogeneity of parameters used to measure various ADs, ${ }^{88-90}$ their rarity, the lack of standard first-line therapy, long-term outcome data of new biological therapies and unified definitions for remission or cure all present challenges in the statistical evaluation of HSCT in AD. Concepts familiar to HSCT practice, such as early TRM, PFS and OS, are unusual to AD specialists, and 'classical' statistical approaches used in HSCT are less easily applied.

Several considerations are important to designing studies of HSCT in AD. Firstly, the definitions of the end point of interest, especially of relapse and progression, need validation. The usual definition of PFS used to evaluate HSCT in oncology includes both relapse and disease progression. In ADs, these two events may be biologically and clinically distinct, and AD-specific metrics require individual consideration, with, for example, relapse in ADs not necessarily resulting in progression to increased disability or death. Secondly, in most chronic AD patients, QoL is frequently the most important parameter and may be assessed using a variety of generic or disease-specific instruments. Although validated, QoL end points may be associated with a high co-efficient of variation, even in the normal population, and the required numbers to achieve statistical power may be significantly increased compared with end points conventionally used in oncology, such as PFS, OS, relapse or death.

Randomized clinical trials (RCTs) are the best method to reveal the effects of a therapeutic intervention and many systematic 'evidence-based medicine' reviews only accept this level of evidence. However, in HSCT in ADs, challenges may arise in unbalanced randomization between 
treatment intensity and TRM risk, the rarity of disease or indication, the assessment of the outcome through an activity score, the definition of drug-free remission and the required duration of follow-up to assess a real benefit. In view of such ethical and practical issues, some important clinical questions are unlikely to be adequately answered by RCTs, and other clinical trial designs may be more appropriate to reassure AD specialists with a view to ultimately establishing large international trials with adequate statistical power.

Therefore, in the context of HSCT in AD, the following alternatives to RCTs may be considered: Prospective cohort studies, which follow a group of patients to assess whether events differ according to prognostic factors and therapeutic options, are the best observational approach and are more reliable than retrospective cohort studies. Casecontrol studies compare a group of patients who experience an event with another not experiencing the same event, and examine how exposure to a suspected agent (for example, therapeutic intervention) differs between groups. This type of study design is useful to ascertain the cause of rare events, although provides weaker evidence than cohort studies.

In non-randomized studies, the major challenge is the avoidance of bias caused by confounding factors linked both to studied factors and to the outcome. For example, observed differences between treatments may be linked to the reason for choosing either treatment may result in selection bias. The statistical method used should adjust the comparisons for all potential prognostic factors, and the causality between treatment and observed difference should be discussed.

\section{Recommendations}

- Well-defined and validated parameters for each type of $\mathrm{AD}$ should be used to define response progression and remission (level III).

- In principle, randomized controlled trials are preferred, but significant challenges should be recognized in their application to HSCT in ADs (level III).

- Prospective non-interventional studies provide an alternative and pragmatic means of increasing clinical knowledge, while eliminating bias associated with retrospective studies (level III).

\section{Health economics}

Despite international variation in health-care provision, all systems have finite and constrained resources and delivery of 'high-cost, low-volume' procedures, such as HSCT, is a public health challenge. Progress in the field of HSCT in ADs has been limited by funding not only of clinical trials, but also of individual HSCT procedures irrespective of the health-care provider.

Previously, standard treatments in many ADs were relatively inexpensive. However, chronic administration of modern biological therapies, potentially for many years, now accumulates substantial costs. Although preliminary health economic and QoL studies have been undertaken, further work is necessary, particularly in conjunction with clinical trials, to determine whether single 'one-hit' intensive HSCT-based treatments may prove cost-effective by preventing, delaying or otherwise limiting the need for biological and other treatments. ${ }^{91-93}$

\section{Recommendations}

- Economic considerations should feature early and prospectively in the planning of clinical trials (level III).

- Studies using other sources of data (registry and established clinical trials) should be used in evaluating the potential cost-effectiveness of HSCT compared with modern non-HSCT treatment options (level III).

\section{Autologous HSCT}

\section{Mobilization of PBSCs for autologous HSCT}

Autologous HSCT can be performed with either PBSC or $\mathrm{BM}$, although use of $\mathrm{BM}$ has been rare, and largely restricted to the paediatric setting. In most ADs, mobilization is safe, but G-CSF alone may induce disease flare. Combining G-CSF with chemotherapy helps prevent flare and improve yields of PBSC with significant decrease of $\mathrm{T}$ cells in the PBSC harvest. ${ }^{94-98}$ No systematic studies analyse the different types of mobilization chemotherapy, but the majority of patients received priming doses of $\mathrm{CY}$ of $2-4 \mathrm{~g} / \mathrm{m}^{2} .{ }^{18}$

PBSCs are more easily mobilized in some AD than others, due to previous treatments or the intrinsic nature of some ADs. Apart from steroids, immunosuppressive, antimitotic or immunomodulatory drugs should be discontinued as early as clinically feasible before mobilization. Careful cardiac evaluation is important before use of mobilizing CY, especially in SSc and SLE, or in MS after use of mitoxantrone: electrocardiogram, cardiac ultrasound and, for SSc, pulmonary artery pressure, $24 \mathrm{~h}$ electrocardiogram, gating and magnetic resonance imaging (MRI) evaluation should be evaluated in view of early reports of potentially fatal cardiac toxicity, which decreased since the consensus statement concerning cardiotoxicity occurring during HSCT for ADs. ${ }^{99}$

In patients with JIA, life-threatening and fatal macrophage activation syndrome was reported both during mobilization of PBSC and following engraftment of PBSC. ${ }^{47,36,100}$ Extreme care should be exercised giving any form of mobilization chemotherapy to severe immune thrombocytopenia (ITP) or Evans' syndrome patients as these states are refractory to platelet transfusion and fatal bleeding reported. ${ }^{101}$ In Crohn's disease, reported episodes of potentially life-threatening sepsis during neutropenia after mobilization, ${ }^{102,103}$ and consideration should be made to antibiotic prophylaxis and close monitoring, with a low threshold for in-patient admission.

\section{Recommendations}

- Autologous HSC may be derived from peripheral blood or BM. Mobilized PBSCs are preferred based on ease of procurement and better engraftment characteristics (level II). 
- Mobilization procedures and stem cell processing should be performed in JACIE (or equivalent) accredited collection centres (level III).

- Priming chemotherapy is recommended to enhance mobilization while maintaining disease control and to prevent potential flare, which may be a consequence of G-CSF alone (level I).

- The recommended mobilization regimen is CY at $2-4 \mathrm{~g} /$ $\mathrm{m}^{2}$ with uromixetan (Mesna) and cautious hyperhydration followed by G-CSF 5-10 $\mu \mathrm{g} / \mathrm{kg}$ (level II).

- A minimum dose of $2 \times 10^{6} / \mathrm{kg} \mathrm{CD} 34+$ cells should be reinfused, irrespective of any graft manipulation (level II).

- Back-up harvest is recommended, especially when graft manipulation has been undertaken (level III).

- When CY-primed mobilization fails, a second attempt at PBSC mobilization or BM harvest should be considered following avoidance of immunosuppressive drugs, where possible. Despite the lack of evidence in patients with $\mathrm{AD}$, the use of plerixafor and G-CSF may be reasonable in poor mobilizers after weighing up the benefits and risks. Steroid cover should be considered to reduce risk of disease flare related to G-CSF. Cases of failure from mobilization should be reported to the EBMT or other registry (level III).

- Mobilization may be associated with increased risk of mortality and morbidity in ADs:

- Caution should be exercised in SSc and SLE, where CY priming may be associated with potentially fatal cardiac complications (level II).

- Caution should be exercised in any patient with ITP (primary or secondary), in whom mobilization with CY may be associated with potentially life-threatening bleeding events (level II).

- Caution should be exercised in patients with CD undergoing mobilization who appear to be at increased risk of severe infection. Consideration should be made for antibiotic prophylaxis and increased monitoring or in-patient admission (level III).

\section{Conditioning regimens for autologous HSCT}

The original guidelines proposed that centres restricted their initial studies to one of four 'standard' HSCT regimens used in haemato-oncology and aplastic anaemia: Although TBI had been the focus of many animal studies and had potential advantages, excess toxicity was acknowledged to be an issue. ${ }^{104}$ In the EBMT registry analyses, most patients had received high-dose CY-based regimens, mainly directed against rheumatological conditions (SSc, RA, SLE). The most commonly used regimen was the 'BEAM' regimen (BCNU $300 \mathrm{mg} / \mathrm{m}^{2}$ on day -6 , Ara-C $200 \mathrm{mg} / \mathrm{m}^{2}$ and etoposide $200 \mathrm{mg} / \mathrm{m}^{2}$ on day -5 to -2 , melphalan $140 \mathrm{mg} / \mathrm{m}^{2}$ day -1 ), principally for MS, where it was frequently combined with anti-T globulin (ATG). Use of TBI was relatively rare $(6 \%)$, but featured significantly in the treatment of JIA $(45 \%)$.

Conditioning regimens were divided retrospectively into (a) 'high intensity', including TBI or high-dose busulphancontaining regimens, (b) 'low intensity', referring to $\mathrm{CY}$ alone, melphalan alone and fludarabine-based regimens, or (c) 'intermediate intensity', including other combinations, such as BEAM, and, in most patients, the combined use of ATG with high-dose CY or other chemotherapy. There was a significant relationship between efficacy and intensity, balanced by the inverse relationship with toxicity as reflected by TRM. Overall, 'intermediate intensity' conditioning regimens were associated with significantly improved outcomes compared with 'low-' and 'high-' intensity regimens. ${ }^{17,18}$

Although more profound responses are possible with high-intensity regimens, caution should be exercised given the substantial short- and long-term toxicity. A further analysis of the MS data supports the significantly higher TRM with oral high-dose busulphan. ${ }^{52}$ The use of irradiation-containing protocols outside of clinical trials has been questioned owing to the long-term adverse effects, including malignancies, even after low-dose irradiation. ${ }^{14,82,105-110}$

Allergic reactions to ATG and other serotherapy may be prevented with intermediate-dose corticosteroids. This may be especially important in patients with MS where fever can worsen neurological symptoms. ${ }^{25,111}$

\section{Recommendations}

- Given the relatively high risk of TRM and late effects of 'high-intensity' conditioning regimens (including irradiation at any dose), their use should be restricted to clinical trial setting (level III).

- If a patient is being treated under the EBMT CO category (Tables $2 \mathrm{a}$ and $\mathrm{b}$ ), the following intermediate intensity conditioning regimens provide a balance between safety and efficacy, while facilitating data analysis and clinical trial planning (level II):

- CY $200 \mathrm{mg} / \mathrm{kg}$ with polyclonal or monoclonal anti-Tcell serotherapy is recommended generally; with $\mathrm{CY}$ $120 \mathrm{mg} / \mathrm{kg}$, fludarabine $150 \mathrm{mg} / \mathrm{kg}$ and ATG (or other anti-T-cell serotherapy) as an alternative in paediatrics.

- For MS specifically BEAM + ATG (or other anti-Tcell serotherapy) is recommended.

- Choice of anti-T-cell serotherapy will depend on availability, but may include polyclonal ATG (for example, thymoglobulin, Fresenius and lymphoglobulin type) and MoAbs (for example, alemtuzumab). Consideration should be given to the short- and longterm toxicities of the various types of serotherapy (level II).

\section{Graft manipulation in autologous HSCT}

Lymphocyte depletion of autologous PBSC was originally recommended and its use has been widespread, particularly in the form of CD34 + selection. ${ }^{18}$ Despite the availability of various clinical grade separation devices for graft manipulation, and theoretical concepts supporting the use of $\mathrm{T}$ - or B-cell depletion, none of the EBMT registry outcome analyses to date support ex vivo depletion strategies. A randomized controlled pilot trial in 30 severe RA using 'low-intensity' conditioning with CY $200 \mathrm{mg} / \mathrm{kg}$ showed no benefit for CD34 + selection. ${ }^{34}$ In addition, the selection procedure adds significantly to the cost of an 
autologous procedure and potentially requires additional numbers of $\mathrm{CD} 34+$ cells to be harvested. Given that pathogenetic mechanisms vary between ADs, a tailored approach to graft manipulation within clinical trials may ultimately be appropriate, but for the present there is little to support the routine use of graft manipulation.

\section{Recommendations}

- There is no evidence to support ex-vivo graft manipulation, although decisions can be made on an individual patient basis (level II).

- Ex-vivo graft manipulation should be the focus of clinical trials (level III).

General status for autologous HSCT, infection prophylaxis and supportive care

Patients with ADs often have significantly reduced immunity related to chronic immunosuppressive treatments and intrinsic immune suppression in some diseases, such as SLE and T1D. The profoundly immunosuppressive nature of the conditioning regimens (use of ATG or other anti-Tcell serotherapy), and ex-vivo graft manipulation of the autologous harvest, are associated with increased risk of acquired and re-activated infections. Instances of infections more commonly associated with allogeneic HSCT, including EBV post transplant lymphoproliferative disorder and CMV disease, have been reported..$^{52,112,113}$ In addition, there are also reports of fever being associated with neurological deterioration in patients with $\mathrm{MS},{ }^{25,111}$ and engraftment syndrome has been recognized as an potential issue in patients with ADs. ${ }^{114,115}$

The risks of TRM and other serious complications should be minimized by patient selection and by minimizing infective and other risks with prophylactic, pre-emptive and other supportive care strategies. Facilities for treating patients with AD with autologous HSCT should be broadly similar to those available for allogeneic HSCT practice. Although induction of infertility is not universal, ${ }^{32,116}$ the effect of HSCT on gonadal function is also an important aspect of the pre-HSCT counselling. Although EBMT registry analyses ${ }^{17,18}$ have shown that PFS improves in younger age groups ( $<35$ years), there is no evidence upon which to base an upper age limit.

\section{Recommendations}

\section{(a) Exclusion criteria for $S C T$}

\section{(i) Organ dysfunction}

- Pre-HSCT evaluation of heart, lung, kidney and gastrointestinal function appropriate to the $\mathrm{AD}$ is critically important. Patients with advanced cardiac disease (left ventricular ejection fraction $<50 \%$ in SSc, $<40 \%$ in other indications, uncontrolled ventricular arrhythmias, pericardial effusions $>1 \mathrm{~cm}$ ), renal insufficiency (creatinine clearance $<40 \mathrm{~mL} / \mathrm{min}$ per $\mathrm{m}^{2}$ in $\mathrm{SSc}$ or $<30 \mathrm{~mL} / \mathrm{min}$ per $\mathrm{m}^{2}$ in other indications), respiratory disease (diffusing capacity of the lung for carbon monoxide $<40 \%$ predicted, mean pulmonary artery pressure $>50 \mathrm{mmHg}$ in $\mathrm{SSc}$ or clinical/subclinical ventilatory impairment due to respiratory muscle involvement in MS) or active gastrointestinal bleeding should be excluded (level II).

\section{(ii) Uncontrolled infection}

- Any uncontrolled acute or chronic infection, including HIV, human T-lymphotropic virus type 1 and 2, hepatitis B surface antigen positivity and hepatitis $\mathrm{C}$ PCR positivity, should be considered as a contraindication (level II).

(iii) Pregnancy

- Pregnancy should always be excluded within 7 days of administering mobilization chemotherapy or HSCT with a blood based $\beta$-human chorionic gonadotrophin assay (level III).

(b) Infections

(i) Diagnostic procedures

Pre-transplant testing

- Pre-transplant workup should include screening for CMV, HSV, VZV, EBV, HIV, human T-lymphotropic virus type 1 and 2, hepatitis viruses and toxoplasmosis in all patients, with other infection screening appropriate for geographical location (level II).

During hospitalization for the HSCT procedure

- CMV Ab-positive patients receiving ATG or other serotherapy, or receiving manipulated autografts, are recommended to undergo CMV PCR or antigenaemia screening for the first 100 days post transplant (level III).

- EBV Ab-positive patients receiving ATG or other serotherapy, or receiving manipulated autografts, are recommended to undergo EBV PCR screening for the first 100 days post transplant, with active surveillance for post transplant lymphoproliferative disease according to local practice (level III).

(ii) Infection prophylaxis In-patient accommodation for HSCT period

- All patients should be accommodated in isolation facilities, with appropriate clean air facilities (for example, laminar flow or HEPA) in accordance with JACIE accreditation standards during BM aplasia/ severe neutropenia (level II).

Bacterial, fungal and viral prophylaxis

- All patients should receive broad-spectrum antibacterial prophylaxis during aplasia (for example, quinolones), anti-fungal prophylaxis (for example, azoles) and herpes prophylaxis (aciclovir) during and for at least 100 days post transplant (level II).

- All patients who are negative for anti-CMV antibodies should receive CMV-negative blood products (level II).

- All patients should receive prophylaxis against Pneumocystis jiroveci (for example, oral co-trimoxazole (TMP/SMX) 3 times weekly as tolerated or, if not tolerated, alternatives, such as nebulized pentamidine, dapsone or atovaquone) for at least 100 days post transplant (level III). 
- All patients positive for anti-toxoplasma antibodies should receive oral co-trimoxazole (TMP/SMX) daily until day -1 , then after reconstitution of blood counts 3 times weekly for at least 100 days post transplant, as tolerated, as per Pneumocystis jiroveci (level II).

- Consideration should be made to risk of reactivation of tuberculosis, with prophylaxis through the period of immune suppression where appropriate (level II).

- I.v. Ig replacement may be considered in carefully selected cases after weighing up the benefits, risks and costs of administration (level III).

(iii) Pre-emptive therapy

- CMV reactivation (diagnosed by PCR or Ag) should be treated with ganciclovir, valganciclovir or foscarnet according to centre policy and protocols (level II).

\section{(iv) Therapy of fever and proven infections}

- Treatment of fever and established infection should follow centre policy and protocols (level III).

- Administration of ATG or other serotherapy should be accompanied by an intermediate dose of corticosteroids. Fever and other reactions, which may result in neurological deterioration in patients with MS, should be promptly treated according to centre policy and protocols (level III).

- When a patient presents a new, high and well-tolerated fever at the time of neutrophil recovery, engraftment syndrome should be considered along with infective causes (level III).

(c) Supportive care

(i) Prophylaxis of haemorrhagic cystitis

- Patients receiving high doses of CY should receive uromixetan (Mesna) and cautious hyperhydration (level I).

\section{(ii) Transfusion}

- Platelet and erythrocyte transfusions should be administered according to centre policy and protocols. Blood products should be irradiated.

\section{(iii) Fertility, pregnancy and menopause}

- Before mobilization and HSCT, consideration should be given to chemotherapy-induced infertility (semen, oocyte or embryo cryopreservation as appropriate) risk of induction of premature menopause, and ultimate need for hormone replacement therapy, where appropriate. Pregnancy should be excluded within 7 days of administering mobilization or conditioning chemotherapy (level III).

(d) Follow-up after HSCT and ongoing responsibility for the patient

- All patients should remain under the direct routine care of the transplant specialist for at least 100 days post transplant, or longer, if necessary until clinically stable. Thereafter, combined care between transplant specialist and referring organ/AD specialist with joint annual review as a minimum is recommended (level III).
Principal indications for autologous HSCT

This section will cover the background and considerations for the main current indications for autologous HSCT, where large-scale multicentre clinical studies are active or are potentially feasible for a proportion of patients. Patients who are unfit for HSCT should be excluded.

Multiple sclerosis. MS is the most frequent chronic inflammatory demyelinating disease, with a prevalence of 1 in 700 adults, believed to be mediated by autoreactive lymphocytes that invade the central nervous system causing damage to oligodendrocytes and axons and resulting in demyelination, neuronal death and brain atrophy. ${ }^{117}$ In the most frequent type, the disease is initially characterized by relapses and remissions due to repeated inflammatory attacks in the central nervous system, as demonstrated by the appearance of new T2-weighted- or contrast-enhancing lesions on MRI studies and characterized pathologically by inflammatory infiltrates rich in $\mathrm{T}$ cells, macrophages/DCs, and, in certain subforms, also in antibodies and complement (relapsing-remitting phase). The second phase is associated with slow progression of disability, with a progressive decline in inflammation (secondary progressive phase), characterized by microglial activation, but predominantly by axonal/neuronal loss. Some patients follow a progressive course from the onset (primary progressive form). The Extended Disability Scoring Scale is the most commonly used means of assessing function and progression in MS. ${ }^{88}$

First-line treatments are the immunomodulators, such as glatiramer-acetate ${ }^{118}$ and $\beta$-IFN, ${ }^{119}$ which delay progression of disability. Very recently, the orally available sphingosine 1 phosphate receptor agonist, fingolimod, which is considerably more effective than $\beta$-IFN and glatiramer-acetate, ${ }^{120}$ has also been approved as first-line therapy. Second-line treatments are mitoxantrone ${ }^{121}$ and the MoAb, natalizumab. ${ }^{122}$ Both first- and second-line treatments alter the natural course of disease by targeting the early phase of inflammation, but virtually all failed to halt the build-up of disability when used in the later secondary progressive phase of disease. The administration of such agents is complicated by infrequent, but sometimes serious, adverse events, such as progressive multifocal leukoencephalopathy with natalizumab, serious infections and other adverse events with fingolimod, and cardiomyopathy and secondary leukaemia with mitoxantrone treatment. ${ }^{123}$ On the horizon are other agents, all aimed at the early inflammatory phase (for example, cladribrine, alemtuzumab, teriflunomide, laquinimod, fumaric acid, ocrelizumab and daclizumab), but those tested in a small population of SPMS (cladribine and alemtuzumab) failed to show effectiveness. Overall, a subset of non-responders has been described in clinical trials with both old and new therapies, associated with the need to maintain long-term immunosuppression.

Since 1996, ${ }^{19}$ HSCT has been extensively reported worldwide as a tool for inducing a prolonged restoration of self-tolerance in MS patients progressing despite ongoing, conventional treatments year. ${ }^{23,25,26,124-128}$ The Autologous Stem cell Transplantation International MS Trial is a multicentre prospective randomized phase II 
study with a primary MRI end point. Despite a low accrual, 21 patients were included and are now followed up by clinical and MRI assessment. ASTIMS was stopped owing to enrolment difficulties, but a prospective phase III trial comparing autologous HSCT vs best approved/ available therapy is currently under consideration between European and North American experts. ${ }^{12,129}$ Most of the patients worldwide have been conditioned with BEAM + ATG schedule showing satisfactory toxicity/ efficacy equipoise. ${ }^{52} \mathrm{CY}$ and ATG conditioning was used for autologous HSCT in 21 early relapsing-remitting patients with low (but not negligible) toxicity. After a range 24-48 months follow-up, patients had no deterioration in the Extended Disability Scoring Scale score, 16/21 were free of relapses and significant improvements in neurological disability were reported. ${ }^{27} \mathrm{~A}$ larger experience is needed to assess the role of lower intensity regimens and a randomized trial is ongoing (http://www.clinicaltrials. gov). A better outcome in relapsing-remitting over secondary progressive forms, including sustained improvement of the disability, has been recently reported in single centre experiences. ${ }^{126,130}$

\section{Recommendations}

- In MS, the ideal target patients for autologous HSCT are in the relapsing-remitting phase, showing high inflammatory activity, both clinically and by MRI $(\mathrm{Gd}+$ contrast-enhancing lesions and/or new T2 lesions in two subsequent scans), who are rapidly deteriorating despite the use of one or more lines of approved treatments (level II).

- Patients with 'malignant' (Marburg type) MS, who develop severe disability in the previous year, are also suitable candidates for autologous HSCT (level II).

- Secondary progressive MS patients should be considered for autologous HSCT only when some inflammatory activity is still evident, that is, either clinical relapses or Gd-enhancing lesions, and/or new T2 MRI lesions on two subsequent scans, and who have shown a sustained and clinically relevant increase in disability in the previous year (level II).

- Patients who have lost the ability to walk (usually an Extended Disability Scoring Scale upper limit of 6.5) must be excluded, except for 'malignant' forms (Marburg type) (level II).

Systemic sclerosis. SSc is a rare AD of unknown origin, with an incidence of 1 in 100000 characterized by skin and visceral (lung, gastrointestinal, cardiovascular and renal) fibrosis secondary to excessive collagen deposition. ${ }^{131}$ Limited and diffuse cutaneous (dcSSc) forms can be distinguished by the extent of skin and organ involvement and auto-Ab profile. ${ }^{132,133}$ Rapidly progressing dcSSc within the first 4 years after disease onset, observed in $10-20 \%$ of cases, is life-threatening disease with 3-5 years survival between 50 and $80 \% .^{134-136}$ Presence of extensive skin thickening (as measured by the Rodnan modified skin score), renal (proteinuria) or lung involvement (as demonstrated by pulmonary functions tests or on CT scan) and high age at onset are important risk factors. ${ }^{135-137} \mathrm{SSc}$ patients only marginally benefit from prolonged oral $\mathrm{CY}$, the only treatment with some proven efficacy. ${ }^{138,139}$

HSCT registry data, case reports and pilot studies in Europe $^{45,48,140}$ and the United States of America ${ }^{22,28}$ in dcSSc consistently showed rapid and sustained clinically relevant improvement of functional ability and skin thickening (in the majority of patients, stabilization of organ function (heart, lung, kidney)), but at the expense of toxicity and early $\mathrm{TRM}^{45}$ in the initial studies. Patient eligibility has been broadly similar in different studies, that is, targeting early dcSSc with a Rodnan modified skin score above 15 and some degree of internal organ involvement (mainly lung) or with rapidly progressing skin fibrosis in the first 2 years after AD onset. Different HSCT regimens have been employed, but most included high doses of CY for mobilization $\left(4 \mathrm{~g} / \mathrm{m}^{2}\right)$ and conditioning $(200 \mathrm{mg} / \mathrm{kg}$ total dose with ATG). Comparison with 'historical controls', including those from recent randomized trials of $\mathrm{CY}$ vs placebo, suggests that autologous HSCT induces more robust and sustained responses of skin involvement and functional status. ${ }^{48,29-31,71,110}$ The benefits need to be weighed against the risks of TRM, which appears to be decreasing with increasing experience and better patient selection, ${ }^{18,99}$ although definitive statements regarding relative safety and efficacy need to await the final analysis of randomized trials.

Two prospective, randomized controlled trials, the multicentre EBMT sponsored ASTIS trial conducted under the auspices of EBMT and European League against Rheumatism in Europe and the single centre ASSIST ${ }^{204}$ study, run by the Chicago group, recently completed recruitment and results are expected by the end of 2011 . The SCOT trial in North America is still accruing. ASTIS and SCOT are large multicentre RCTs with similar eligibility criteria and comparable outcome measures and include control treatment with 12 monthly i.v. pulses CY, but differ in the conditioning regimen being without (ASTIS) or with (SCOT) irradiation, allowing future comparison between intense immunosuppression vs myeloablation. Long-term follow-up of patients in all of these trials is essential to examine possible divergence of survival and to study late effects of treatment.

Although the outcome of juvenile systemic sclerosis is better than the adult form, extensive skin and pulmonary involvement show a 5-year mortality of $10 \% .{ }^{141}$ As with the adult form, immunosuppressive drug strategies may be used, but there is no satisfactory treatment. Autologous HSCT in juvenile systemic sclerosis has been explored in five patients (median age 12 years) incorporated in a larger analysis of SSc. The patients with severe lung disease were treated with CY-based conditioning (120-200 mg/kg) and selected autograft. After a median follow-up of 37 (range 13-67) months, all five children were alive and three of them are in complete and sustained remission. ${ }^{48,54}$

No published data are available to make recommendations for limited SSc patients in any age group.

\section{Recommendations}

- Autologous HSCT can be considered as treatment for selected patients with early dcSSc and juvenile systemic sclerosis (Tables 2a and b) (level II). 
- Patients to be considered for HSCT include those with diffuse SSc with disease duration $\leqslant 5$ years since development of first non-Raynaud's symptoms with a modified Rodnan skin score $\geqslant 15$ plus major organ involvement (with documented evidence of onset or clinically significant worsening in the previous 6 months) as defined by at least one of:

(a) respiratory involvement with a DLCO and/or forced vital capacity $\leqslant 70 \%$ of predicted and evidence of interstitial lung disease (chest X-ray and/or HR-CT scan) (level II)

(b) cardiac involvement with conduction disturbances, including second-/third-degree atrioventricular block, intra-ventricular conduction disturbance, left axis deviation, atrial or ventricular rhythm disturbance, pericarditis as defined by $\leqslant 1 \mathrm{~cm}$ on cardiac ultrasound (level II)

(c) renal involvement with proteinuria $>0.3 \mathrm{~g} / 24 \mathrm{~h}$, not explained by other causes than systemic sclerosis (level II).

Systemic lupus erythematosus. SLE is a heterogeneous chronic AD with a prevalence of 40-50 per 100000 , predominantly females $(>85 \%)$ with higher frequency among people of African origin. ${ }^{142-144}$ The outcome of active severe SLE due to kidney, lung, heart or brain involvement has improved in adults and children with early diagnosis and new immunosuppressive agents combined with overall tighter control of blood pressure and infections. ${ }^{145}$ First-line therapies aimed at inducing remission within the first 6-9 months of disease flare include corticosteroids in combination with mycophenolate mofetil or CY using the classical National Institutes of Health regimen ${ }^{146,147}$ or the Eurolupus regimen, ${ }^{148}$ with lower CY doses for shorter duration and same efficacy. Among other drugs tested for induction, the use of various MoAbs against $\mathrm{T}$ - or B-cell receptors or adhesion molecules all failed to demonstrate their superiority when tested in phase III trials, except for belimumab, an MoAb against Blymphocyte stimulator soluble receptor. ${ }^{149}$

Response rates to standard therapy vary according to the criteria, extent of visceral involvement, ethnic origin and socio-economic profile. Approximately 20\% (10-36\%) of active SLE patients fail to respond; $50 \%(10-65 \%)$ relapse after initial treatment, 5-15\% evolve towards end-stage disease and $10-15 \%$ die at 10 years. ${ }^{150,151}$ Initial and persistent renal, cerebral or severe pulmonary involvement along with overall disease activity are important predictors of poor long-term survival. ${ }^{151,152}$

Among 200 autologous HSCT worldwide for SLE, the largest experience comes from retrospective EBMT ADWP registry $(n=53),{ }^{49}$ and from the Northwestern University prospective single centre study $(n=50)^{153}$ with a $50 \%$ probability of 5-year disease-free survival in both studies. In addition to a decrease in the overall disease activity and serological responses, autologous HSCT reversed pulmonary dysfunction and anti-phospholipid syndrome with durable treatment-free responses lasting 5 or more years on minimal or no treatment. In terms of safety, the Northwestern University study reported TRM of 4\% (2/50, including one death from fungal infection during mobilization), ${ }^{153}$ whereas the first multicentre EBMT analysis showed a more substantial TRM of $12 \%$ in early published cohort of 54 patients analyzed up to $2002,{ }^{49}$ subsequently decreasing by around half in a later cohort of 28 patients transplanted from 2002 to 2008 (D Jayne, personal communication). In the EBMT registry analysis, severe or fatal infections tend to be more frequent among the 85 SLE patients with autologous HSCT as compared with other groups of patients $(39 \%$ vs $22 \%) .{ }^{18}$ In addition, preliminary analysis of 18 paediatric SLE patients in the EBMT database, with 41 months median follow-up after autologous HSCT, confirmed that nine patients are in CR, while seven relapsed and two died of TRM (M Rabusin, personal communication). An updated analysis of the 85 patients reported to the EBMT is in preparation (D Jayne, personal communication).

In summary, in patients with severe SLE refractory to conventional immunosuppressive therapies, autologous HSCT can achieve sustained clinical remissions with qualitative immunological changes ${ }^{153,154}$ not seen with other forms of therapy despite significant TRM. Overall prospective and retrospective data highlight the need for careful patient selection, as well as recognition of the intrinsic immune suppression and other risks associated with advanced SLE. Ideally, the role of autologous HSCT in the treatment of severe SLE in both adults and children should be established in adequately powered RCTs. Until larger international RCTs are available, smaller phase II studies and stronger registry analyses should be pursued to help define a core set of clinical data biological sample collection to be collected in every study.

\section{Recommendations}

- Current uncontrolled data suggest that autologous HSCT can be considered as treatment for carefully selected subpopulations of SLE patients early in their disease course, with reliably predicting poor prognostic factors, according to combinations of demographic, clinical and laboratory markers (Tables $2 \mathrm{a}$ and b) (level II).

- Patients to be considered for HSCT would reasonably include those with sustained or relapsed active BILAG category A SLE remaining steroid dependent after at least 6 months of the best standard therapy, using mycophenolate mofetil or CY with or without antiCD20 and other MoAbs, with documented evidence of visceral involvement or refractory SLE as defined by at least one of:

(a) Kidney involvement: meeting the criteria for BILAG category A with a renal biopsy of less than 12 months showing evidence of World Health Organization class III or IV glomerulonephritis (level II).

(b) Any other type of vital organ involvement with BILAG neurological category A, cardiovascular or pulmonary category A, vasculitis category A and autoimmune cytopenias category A (level II).

(c) Associated anti-phospholipid syndrome with recurrent thromboembolism despite maximal anticoagulation (level III). 
Crohn's disease. CD is an inflammatory bowel disease affecting both adults and children characterized by a chronic clinical course, with exacerbations and remissions, and by a trans-mural inflammation that may affect different segments of the digestive tract. In developed countries, prevalence of CD is around $0.1 \%$. Recent genetic discoveries have underlined the role of innate and adaptive immunity, as well as epithelial function. Nevertheless, the pathogenesis of $\mathrm{CD}$ and the role of environmental factors remain unclear. Current pharmacological treatments based on corticosteroids, immunosuppressants (for example, thiopurines and MTX) and biological therapies (particularly anti-tumour necrosis factor drugs) are used early in the course of the disease.

Despite the major recent progress in the treatment of $\mathrm{CD}$, some patients fail all available therapies, including immunosuppressants and biological therapies. There is a subset of patients in whom the disease runs an aggressive course with progressive tissue damage and potentially reduced life expectancy. ${ }^{155-158}$ Surgery may be considered as an option in many cases, but may lead to short bowel syndrome or to a definitive stoma, which may be refused by the patient.

Beyond case reports and short series, autologous HSCT as primary treatment for CD has been investigated in several phase II studies, one with extended follow-up. ${ }^{38-40,102}$ The majority of patients have been adult, although paediatric patients have also been treated (Table 1). Responses have been encouraging and prolonged, but the progressive incidence of relapse with long-term follow-up raises questions regarding the benefits over conventional treatments and also in relation to salvage and maintenance treatments post-HSCT. ${ }^{159}$

ASTIC is a multicentre, prospective, randomized phase III study for adult patients with CD supported by European Crohn's and Colitis Organization and sponsored by EBMT comparing the relative benefits of autologous HSCT with best available medical therapy. In addition, paediatric specialists have proposed the following consensus criteria for refractory disease (a) corticosteroid-resistant disease, with no response to equivalent prednisolone dose of $1 \mathrm{mg} / \mathrm{kg}$ daily (max $60 \mathrm{mg}$ daily) for 8 consecutive weeks, or corticosteroid dependence or relapse within 3 months of stopping treatment and (b) lack of response to, or intolerance of, at least one of; azathioprine or mercaptopurine for 4 consecutive months, MTX for 3 consecutive months, infliximab $(5 \mathrm{mg} / \mathrm{kg})$ given as $0,+2$ and +6 weeks regimen infusions, or thalidomide $2 \mathrm{mg} / \mathrm{kg}$ for 8 consecutive weeks. ${ }^{54}$

\section{Recommendations}

- In the absence of results from large studies, autologous HSCT should be reserved for patients with severe CD unresponsive to multiple lines of therapy, including immunosuppressive agents and anti-tumour necrosis factor MoAbs (Tables 2a and b) (level II).

- HSCT may be considered for patients with active CD refractory to immunosuppressants and biologics. The disease activity has to be proven by morphological evaluation (endoscopy, CT scan). Other therapeutic options, including surgery, should be discussed case by case, whenever acceptable. Autologous HSCT may be considered for the following situations (level III):

- Active disease, uncontrolled by medical therapies.

- Extensive disease in which surgical resection would expose the patient to the risk of small bowel syndrome.

- Refractory colonic disease and perianal lesions where coloprotectomy with a definitive stoma not accepted by the patient.

- Paediatric CD requires special consideration and appropriate expertise in patient selection (level III).

Orphan diseases and rare indications for autologous HSCT In other ADs, the strength of established competing therapies and the limited evidence base have made HSCT a rare consideration. Rare cases of resistant disease may be considered in a multidisciplinary setting within the ' $\mathrm{CO}$ ' category. Enrolment onto a clinical trial should be pursued, if feasible. Full data reporting to EBMT or equivalent registry is mandatory, and will facilitate prospective noninterventional studies in these indications.

Autoimmune cytopenias. The majority of patients with immune cytopenia respond well to treatment, and many require no intervention, but occasionally necessitate high levels of immunosuppression and supportive care with lifethreatening situations. ITP is the most common autoimmune cytopenia, with an incidence of the chronic form of 5.8-6.6 per 100000 in adults and 0.46 per 100000 in children. ITP in children follows a chronic course in $25 \%$ of patients, and $10 \%$ require chronic immunosuppressive therapy. ${ }^{160,161}$ Autoimmune haemolytic anaemia (AIHA) is less frequent with an incidence of 2.6/100000. ${ }^{162}$ Paediatric AIHA follows a chronic course in $20 \%$ of patients between 2 and 12 years, with a reported mortality rate of $10 \% .^{163}$ Evans' syndrome and thrombotic thrombocytopenic purpura are rarer, but more frequently associated with life-threatening complications with a mortality rate in children up to $30 \% .{ }^{163}$

Among 52 patients with ITP, AIHA and Evans' syndrome in the EBMT registry, who underwent autologous or allogeneic HSCT up to 2008 in 50 centres, OS at 5 years was $61 \pm 5 \%$. Analysis of the 24 children with immune cytopenias (19 allogeneic HSCT and 7 autologous HSCT) confirmed a $60 \%$ PFS with allogeneic HSCT vs $35 \%$ with autologous HSCT, with a TRM of $20 \%$ overall. $^{54,164}$ It remains unclear whether symptomatic 'cytopenia-free survival' is best achieved with autologous or allogeneic HSCT, $51,161,165$ but, given the low number of HSCT per centre, it is unlikely that a prospective study can ever be successfully completed. Some patients have clearly benefited and harmonizing procedures may yield more interpretable data in the future through prospective non-interventional protocols.

\section{Recommendations}

- HSCT may be considered for patients with ITP, AIHA and Evans' syndrome refractory to at least two lines of 
treatment (including rituximab and TPO receptor agonists for ITP) under the 'CO' criterion (Tables $2 \mathrm{a}$ and b) (level II).

- For adults under 50 years, autologous HSCT should be considered if no HLA-matched sibling donor is available and is preferred over alternative donor HSCT (level II).

- For paediatric patients, autologous HSCT is an option in patients with autoimmune cytopenia, where no fully HLA-compatible sibling or unrelated donor can be identified, or in patients with Evans' syndrome with no 9/10 HLA-matched unrelated donor (level II).

Juvenile idiopathic arthritis. JIA is the most common rheumatic disease in children and a major cause of disability. In $5-10 \%$ of children with the systemic and polyarticular onset forms, the disease is refractory to nonsteroidal anti-inflammatory drugs and immunosuppressive drugs such as MTX and corticosteroid with an estimated mortality in the whole group of $2-4 \%$. The introduction of biological agents, such as anti-tumour necrosis factor and anti-IL-1 and -6 receptor agents, had a major impact on outcome of children with the polyarticular form, but is less effective in active systemic disease. ${ }^{166,167}$

A retrospective European analysis included 34 JIA patients undergoing autologous HSCT using ATG, and CY \pm low-dose TBI (4 Gy) and T-cell depletion. ${ }^{47}$ Over half the patients achieved a complete drug-free remission, while another six patients $(18 \%)$ showed a partial response. The incidence of complications was high with three episodes of fatal haemophagocytic (macrophage activation) syndrome and TRM of $9 \%$. Long-term remission has been confirmed in the majority of patients. ${ }^{47,36,100,37}$

\section{Recommendations}

- HSCT can be considered as treatment for carefully selected subpopulations of patients with JIA who meet the following inclusion criteria under the ' $\mathrm{CO}$ ' criterion (Table 2b):

- systemic onset with polyarticular course or polyarticular onset,

- corticosteroid-resistant disease defined as no response to equivalent prednisone dose of $2 \mathrm{mg} / \mathrm{kg}$ per day (max $60 \mathrm{mg}$ daily) for 8 consecutive weeks,

- inadequate response to, or intolerance to, at least two disease-modifying antirheumatic drugs, including biological agents such as etanercept, infliximab, adalimumab, anti-IL-1 receptor and anti-IL-6 receptor agents, and

- unacceptable toxicity from disease-modifying antirheumatic drugs or corticosteroid therapy (level II).

- Patients with a history of previous macrophage-activating syndrome or recent systemic disease flare should receive ciclosporin together with maintenance prednisone during the conditioning regimen phase before the transplant (level II).

Rheumatoid arthritis. Before the widespread introduction of biological therapy, severe RA was the most common indication for autologous HSCT. The procedure was well tolerated and produced good initial responses, but early relapses were observed necessitating re-introduction of anti-rheumatic treatments. Seronegative disease was more responsive with some prolonged remissions. The EBMT supported the phase III ASTIRA trial to address the role of post transplant maintenance, but, in the midst of emerging biological therapy, it recruited poorly and was closed. Sporadic patients continue to be reported to the registry, but the place of HSCT is unclear. ${ }^{50,34,168-170}$ Exceptional patients may be considered on a ' $\mathrm{CO}$ ' basis, and data registration is a minimum recommendation (Table $2 \mathrm{a}$ ).

Systemic vasculitis. The systemic vasculitides are heterogeneous collection of diseases, including Behçet's disease, Wegener's granulomatosis, cryoglobulinaemia, ChurgStrauss angiitis, polychondritis, Takayasu arteritis, polyarteritis nodosa and undifferentiated vasculitis, occasionally life-threatening. A retrospective registry-based analysis summarized 14 patients with active, resistant disease who received a first autologous HSCT for various forms of vasculitis. Responses were seen, with half of the patients being complete responders, ${ }^{53}$ in the various subtypes of vasculitis with autologous HSCT. ${ }^{171-175}$ Despite limited evidence, autologous HSCT may be considered on a ' $\mathrm{CO}$ ' basis in patients with systemic vasculitis after failure of at least two lines of conventional treatment with data registration a minimum recommendation (Tables $2 \mathrm{a}$ and $\mathrm{b}$ ).

Dermatomyositis and polymyositis. Among the eight cases of polymyositis and dermatomyositis registered in the EBMT database, there are some encouraging anecdotal responses, especially in children, but others in adults are disappointing. ${ }^{176-179}$ No definitive recommendations can be made other than that exceptional patients may be considered on a 'CO' basis, and data registration is a minimum recommendation (Tables $2 \mathrm{a}$ and $\mathrm{b}$ ).

Chronic demyelinating inflammatory polyneuropathy and neuromyelitis optica. Chronic demyelinating inflammatory polyneuropathy may be chronically disabling and resistant to treatment. In such cases, autologous HSCT has resulted in improvement or stabilization of neurological status and cessation of immunosuppression. ${ }^{180-182}$ Achieving an accurate diagnosis of chronic demyelinating inflammatory polyneuropathy as per the European Federation of Neurological Societies guidelines with an active inflammatory component is mandatory. ${ }^{183}$

Among the limited published and EBMT registry data for HSCT in neuromyelitis optica registered in the EBMT database, anecdotal responses of neuromyelitis optica to HSCT were encouraging, although relapse may not be prevented. ${ }^{184,185}$

The very limited evidence of autologous HSCT in both chronic demyelinating inflammatory polyneuropathy and neuromyelitis optica make any robust clinical recommendations difficult, but given some favorable reported outcomes, treatment-resistant cases may reasonably be considered on a ' $\mathrm{CO}$ ' basis involving both experienced neurologists and haematologists. 


\section{Recommendations}

- Patients with orphan diseases or rare indications may be considered for treatment as a 'CO' (Tables 2a and b), although enrolment onto a prospective clinical trial or prospective non-interventional study is highly recommended, whenever possible (level III).

- Long-term formalised follow-up of all patients using HSCT registries (for example, EBMT MED-A/B reporting) is a minimum recommendation (level II).

\section{Evolving indications for autologous HSCT}

Type 1 diabetes mellitus. T1D results from a cell-mediated autoimmune attack against pancreatic $\beta$-cells. The incidence of T1D in children in Europe varies between 5 and 40 per 100000 new cases per year. Patients with T1D depend on exogenous insulin administration for survival and the best established treatment is tight control of blood sugar accomplished by either frequent daily injections or continuous s.c. infusion of insulin, that is, intensive insulin therapy, which reduces the risk of retinopathy, nephropathy and neuropathy by $35-90 \%$ when compared to conventional therapy with 1-2 insulin injections per day. ${ }^{186,187}$

Autologous HSCT has been explored among other immunotherapeutic approaches aiming at re-inducing tolerance at the time of early onset of T1D and encouraging persistence of $\beta$-cell function, which improves outcomes. ${ }^{188}$ In Brazil, 20 patients with new onset T1D presenting without ketoacidosis or steroid exposure were treated with autologous HSCT without TRM, 12 patients experiencing sustained insulin independence, normal $\mathrm{HbA1C}$ and increased C-peptide levels. ${ }^{41,42,189}$ In the EBMT database, 10 T1D cases are registered with initial outcomes reflecting similar feasibility and safety of autologous HSCT. ${ }^{43}$

Refractory type II coeliac disease. Coeliac disease affects around $0.5-1 \%$ of the population, the vast majority of patients being succesfully managed with a gluten-free diet, ${ }^{190}$ but a small proportion of patients $(2-5 \%)$ are refractory. Immunophenotyping of intraepithelial lymphocytes in the small bowel can differentiate refractory type II coeliac disease patients with aberrant phenotype, lacking surface expression of CD3 and CD8, at high risk of developing enteropathy-associated T-cell lymphoma. Based on the poor prognosis of enteropathy-associated T-cell lymphoma, 18 patients with refractory type II coeliac disease resistant to cladribine were identified, and 13 underwent melphalanbased conditioning and autologous HSCT, resulting in improvement in clinical and laboratory parameters, despite one patient suffering TRM and one patient developing enteropathy-associated T-cell lymphoma after 4 years. Improvement in prognosis was supported by mortality from enteropathy-associated T-cell lymphoma in the five patients who did not receive autologous HSCT. ${ }^{191,192}$

\section{Recommendation}

- T1D and coeliac disease are relatively common ADs, but the role of autologous HSCT remains unclear. Patients should only be treated on an IRB/REC-approved prospective clinical trials (level III).

\section{Allogeneic and syngeneic HSCT}

Allogeneic HSCT has rarely been used in the treatment of AD, and syngeneic HSCT, even more rarely. Whereas syngeneic HSCT offers as means of lymphohaemopoietic replacement with risks to the patient no greater than autologous HSCT and potential greater benefit in some, ${ }^{193-195}$ various forms of allogeneic HSCT are associated with toxicity and TRM risks, which far outweigh the risks of most patients with severe ADs. The area where allogeneic HSCT has mostly been used has been in the context of immune cytopenia, predominantly in the paediatric setting where unrelated and cord blood procedures are reported. ${ }^{44,51,196}$ Donor lymphocyte infusions have also been used to demonstrate the principle of graft-vs-autoimmune effect. ${ }^{44,57,60}$ Some patients clearly benefited from the procedure, despite substantial overall toxicity. It is unclear whether a prospective trial can ever be successfully completed in this area, but harmonising the procedures through a prospective non-interventional international protocol is warranted.

Only anecdotal data are available in SSc, SLE, RA and vasculitis, ${ }^{197-202}$ precluding any conclusions or recommendations. Given the high risk of TRM and also potential chronic reduction in QoL, previous consensus has discouraged allogeneic HSCT outside of a clinical trial. ${ }^{59}$

\section{Recommendations}

- Centres performing donor HSCT for ADs should have appropriate JACIE accreditation or equivalent (level II).

- Syngeneic HSCT may be considered as an alternative to autologous HSC, with comparable risks and potential greater benefit. Donor-related issues are an important consideration (level II).

- Allogeneic HSCT outside of a clinical trial is highly discouraged in all ADs. In exceptional circumstances, allogeneic HSCT may be considered for patients with ITP, AIHA and Evans' syndrome refractory to at least two lines of treatment (including rituximab and TPO receptor agonists for ITP) under the ' $\mathrm{CO}$ ' criterion (Tables 2a and b) (level III).

- In adults under 50 years with life-threatening autoimmune cytopenia, allogeneic HSCT may be considered if an HLA-identical sibling donor is available. In patients for whom no donor can be identified, autologous HSCT is preferred over alternative donor HSCT (level III).

- In paediatric patients with life-threatening autoimmune cytopenia, allogeneic HSCT may be considered if an HLA-identical sibling donor is available. In Evans' syndrome, unrelated/alternative donor HSCT from a well-matched unrelated donor (with at least 9/10 compatible loci by 4 digit/allele high-resolution typing) may be considered (level III).

- BM or umbilical cord blood is recommended as graft source for allogeneic HSCT in autoimmune cytopenia (level II).

- Recommended conditioning for HLA-matched sibling HSCT is with CY $120 \mathrm{mg} / \mathrm{kg}$, fludarabine $150 \mathrm{mg} / \mathrm{kg}$ and ATG (or other anti-T-cell serotherapy) (level III).

- In the paediatric unrelated/alternative donor setting, a sufficiently immunosuppressive regimen should be selected by the responsible clinician. Based on other areas of paediatric HSCT (metabolic disorders and 
haemoglobinopathies), fludarabine $4 \times 35 \mathrm{mg} / \mathrm{m}^{2}$, thiotepa $10 \mathrm{mg} / \mathrm{kg}$ and melphalan $140 \mathrm{mg} / \mathrm{m}^{2}+\mathrm{ATG}$ is one option. Decision making should be individualized based on local experience and donor/recipient factors (level III).

\section{Conclusions and future directions}

There is now well 15 years of clinical experience of HSCT in patients with various severe ADs. The field has brought about fruitful multidisciplinary collaborations to address one of the most challenging of groups of patients in clinical practice. In parallel, scientific studies have started to elucidate mechanisms of reset and control of dysfunctional immune systems. However, the evolving industry of biological and smallmolecule drugs has proved a constant challenge to establishing the role of HSCT in severe AD. Only when efficacy is formally demonstrated by controlled studies balancing the acute risks of HSCT vs the toxicity of chronic immunosuppressive treatment will HSCT be perceived as an alternative to, or reasonable escalation step after failure of standard treatment. Lessons previously learnt from the inability to demonstrate benefit of autologous HSCT in breast cancer ${ }^{16}$ are pertinent to HSCT for ADs, although the rarity and heterogeneity of AD warrants a challenging and pragmatically balanced approach. Long-term outcomes of efficacy and

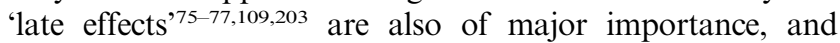
health economic considerations should be central to the development of therapeutic strategies. ${ }^{92}$ Ultimately, novel biological, HSCT and other cellular therapy-based approaches should not be mutually exclusive, and optimal outcomes may be achieved with combinations of intensive treatments combined with long-term consolidation and maintenance approaches. For the present time, it is intended that these guidelines and recommendations will promote patient safety and facilitate harmonisation of procedural aspects, patient selection, data collection and coordination of prospective studies, with the aim of identifying the most appropriate clinical niche of HSCT in each AD, as well as supporting basic scientific research endeavours.

\section{Conflict of interest}

GM received honoraria for lecturing, travel expenses for attending meetings and financial support for research from Bayer Schering, Biogen Idec, Sanofi-Aventis, Merck Serono and Novartis Pharmaceuticals. RM has received grant support or financial compensation for advisory services to companies, who market drugs for MS. These include TEVA/Sanofi-Aventis, Biogen, Merck \& Serono and Novartis. JM van Laar has received speaker's fees from Amgen and Miltenyi-Biotec. The remaining co-authors disclose no conflicts of interest.

\section{Acknowledgements}

The co-authors have contributed as follows: JAS (ADWP Secretary), RS (previous ADWP Chair) and DF (current ADWP
Chair) proposed, coordinated and led the writing and overall editing of the document. MRa and CP (on behalf of the Paediatric Diseases Working Party) led, wrote and integrated the sections relevant to paediatrics; RS, GM and RM wrote and led the MS section and had oversight of the other neurological sections. JvL, CD and DF led the systemic sclerosis section and RC and DF led the SLE section, and all had oversight of the rheumatological sections. JP and MRa led and had oversight of the sections relating to immune cytopenias. MA, SA, CJH and MRa wrote and led the CD section. JAS, RS and DF led and wrote the T1D and coeliac disease sections; ML led and wrote the statistical aspects section. RA, MR, RS, JJM and JAS led the generic haematological and specialist HSCT aspects, including infection prophylaxis and supportive care sections. All co-authors have reviewed the entire document and provided input appropriate to their specialization. The co-authors wish to acknowlege Manuela Badoglio for her input in respect to data management and referencing, and Enric Carreras and Majid Kazmi for expert advice and comments.

The co-authors wish to acknowledge the contributions of the following discussants from Europe and North America who participated in the workshops in Florence 2009, and in the EBMT ADWP Meeting of October 2010, which helped to inform the writing of the guidelines document.

Multiple sclerosis: Gianluigi Mancardi, Department of Neurology, S Martino Hospital, Genova, Italy; Harry Atkins, Ottawa Health Research Institute, Ottawa, Ontario, Canada; Mark Freedman, MS Research Clinic, Ottawa Hospital Research Institute, Ottawa, Canada; Maria Pia Amato, Neurology Department, Careggi University Hospital, Florence, Italy; Enric Carreras, Haematology Department, Hospital Clinic, Barcelona, Spain; Athanassios Fassas, Haematology Department, Thessaloniki, Greece; Roland Martin, Institute for Neuroimmunology and Clinical MS Research, Hamburg, Germany; Luca Massacesi, Neurology Department, Careggi University Hospital, Florence, Italy; Paolo Muraro, Division of Neuroscience and Mental Health, Imperial College, London, UK; Maria Pia Sormani, Department of Biostatistics, University of Genoa, Italy; Douglas Kerr, Neurology Department, Johns Hopkins TM Center, Baltimore, MD, USA; Richard Nash, Fred Hutchinson Transplant Center, Seattle, WA, USA; Linda M Griffith, Division Allergy, Immunology and Transplantation, NIAID, National Institutes of Health, Bethesda, MD, USA; Marcelo Pasquini, CIBMTR, Wisconsin Medical College, Milwaukee, WI, USA. Systemic sclerosis and SLE; Andrea Doria, Division of Rheumatology, University of Padova, Italy; David Jayne, Nephrology and Vasculitis, Addenbrooke's Hospital, Cambridge, UK; Alberto Marmont, Department of Haematology, Ospedale di San Martino, Genoa, Italy; Thierry Martin, Nouvel Hôpital Civil de Strasbourg, Service de Médecine Interne et d'Immunologie Clinique, Strasbourg, France; Alan Tyndall, Professor and Head University, Department of Rheumatology, Basel, Switzerland; Alexander, E Voskuyl, $\mathrm{Vu}$ University Medical Center, Amsterdam, The Netherlands; Maureen Mayes, Professor of Internal Medicine, Division of Rheumatology, University of Texas-Houston Health Science Center, Houston, TX, USA; Keith Sullivan, Professor of Medicine, Duke University Medical Center, Durham, NC, USA. Crohn's disease: M Allez, Paris, S Ardizzone, Milan, Massimo Di Gioia, Haematology Department, Careggi University Hospital, Florence, Italy; Barbara Motta, Fondazione Ospedale Maggiore Policlinico, University of Milan, Milan, Italy; Francesco Onida, Fondazione Ospedale Maggiore Policlinico,University of Milan, Milan, Italy; Montserrat Rovira, BMT Unit Hematology Department Hospital Clinic, Barcelona, Spain. Autoimmune cytopenia; C Bitetti, Fondazione Centro S Raffaele, Milan, Italy; F Gualandi, 
Ospedale di San Martino, Genoa, Italy; USA; J Storek, University of Calgary, Calgary, Alberta, Canada. ADWP Meeting Paris 15 October 2010: Dominique Farge, John Snowden, Emilian Snarski, Elena Ricart, Susanna Pinó Donay, Marco Rabusin, Thierry Martin, Riccardo Saccardi, Ivan Foeldari, Caroline Lindemans, Marcello Pasquini, Jaap Van Laar, Alexander. T Voskuyl, Jan Voswinkel, David Pohlreich, Francesca Gualandi, Antoine Toubert, Renate Arnold, Montserrat Rovira, Falk Hiepe, Thomas Daikeler, Peter Hassebalt, Manuela Badoglio, Henning Trawinski, Margaret Soogrim, Attilio Bondaza, Laurence Michel, Mats Brune, Cristina Castilla Llorente, Majid Kazmi, Francesco Oneda.

\section{References}

1 Ikehara S, Good RA, Nakamura T, Sekita K, Inoue S, Oo $\mathrm{MM}$ et al. Rationale for bone marrow transplantation in the treatment of autoimmune diseases. Proc Natl Acad Sci USA 1985; 82: 2483-2487.

2 Marmont AM, Van Bekkum DW. Stem cell transplantation for severe autoimmune diseases: new proposals but still unanswered questions. Bone Marrow Transplant 1995; 16: 497-498.

3 Karussis DM, Vourka-Karussis U, Lehmann D, Abramsky O, Ben-Nun A, Slavin S. Immunomodulation of autoimmunity in MRL/lpr mice with syngeneic bone marrow transplantation (SBMT). Clin Exp Immunol 1995; 100: 111-117.

4 Burt RK, Burns W, Ruvolo P, Fischer A, Shiao C, Guimaraes A et al. Syngeneic bone marrow transplantation eliminates $\mathrm{V}$ beta $8.2 \mathrm{~T}$ lymphocytes from the spinal cord of Lewis rats with experimental allergic encephalomyelitis. J Neurosci Res 1995; 41: 526-531.

5 Burt RK, Padilla J, Begolka WS, Canto MC, Miller SD. Effect of disease stage on clinical outcome after syngeneic bone marrow transplantation for relapsing experimental autoimmune encephalomyelitis. Blood 1998; 91: 2609-2616.

6 van Bekkum DW. Stem cell transplantation in experimental models of autoimmune disease. J Clin Immunol 2000; 20: $10-16$.

7 van Bekkum DW. Stem cell transplantation for autoimmune disorders. Preclinical experiments. Best Pract Res Clin Haematol 2004; 17: 201-222.

8 Snowden JA, Patton WN, O’Donnell JL, Hannah EE, Hart DN. Prolonged remission of longstanding systemic lupus erythematosus after autologous bone marrow transplant for non-Hodgkin's lymphoma. Bone Marrow Transplant 1997; 19: $1247-1250$.

9 Marmont AM. Immunoablation followed or not by hematopoietic stem cells as an intense therapy for severe autoimmune diseases. New perspectives, new problems. Haematologica 2001; 86: 337-345.

10 Marmont A, Tyndall A, Gratwohl A, Vischer T. Haematopoietic precursor-cell transplants for autoimmune diseases. Lancet 1995; 345): 978.

11 Tyndall A, Gratwohl A. Blood and marrow stem cell transplants in auto-immune disease: a consensus report written on behalf of the European League against Rheumatism (EULAR) and the European Group for Blood and Marrow Transplantation (EBMT). Bone Marrow Transplant 1997; 19: 643-645.

12 Pasquini MC, Griffith LM, Arnold DL, Atkins HL, Bowen JD, Chen JT et al. Hematopoietic stem cell transplantation for multiple sclerosis: collaboration of the CIBMTR and EBMT to facilitate international clinical studies. Biol Blood Marrow Transplant 2010; 16: 1076-1083.
13 Saccardi R (ed). Haematopoietic stem cell transplantation for severe AD. Bone Marrow Transplant 2010; 45: 1:S1-1:25.

14 Burt RK, Marmont A, Oyama Y, Slavin S, Arnold R, Hiepe F et al. Randomized controlled trials of autologous hematopoietic stem cell transplantation for autoimmune diseases: the evolution from myeloablative to lymphoablative transplant regimens. Arthritis Rheum 2006; 54: 3750-3760.

15 Sun L. Stem cell transplantation: progress in Asia. Lupus 2010; 19: 1468-1473.

16 Gratwohl A, Baldomero H, Aljurf M, Pasquini MC, Bouzas LF, Yoshimi A et al. Hematopoietic stem cell transplantation: a global perspective. JAMA 2010; 303: 1617-1624.

17 Gratwohl A, Passweg J, Bocelli-Tyndall C, Fassas A, van Laar JM, Farge D et al. Autologous hematopoietic stem cell transplantation for autoimmune diseases. Bone Marrow Transplant 2005; 35: 869-879.

18 Farge D, Labopin M, Tyndall A, Fassas A, Mancardi GL, Van Laar $\mathbf{J}$ et al. Autologous hematopoietic stem cell transplantation for autoimmune diseases: an observational study on 12 years' experience from the European Group for Blood and Marrow Transplantation Working Party on Autoimmune Diseases. Haematologica 2010; 95: 284-292.

19 Fassas A, Anagnostopoulos A, Kazis A, Kapinas K, Sakellari I, Kimiskidis $\mathrm{V}$ et al. Peripheral blood stem cell transplantation in the treatment of progressive multiple sclerosis: first results of a pilot study. Bone Marrow Transplant 1997; 20: 631-638.

20 Fassas A, Anagnostopoulos A, Kazis A, Kapinas K, Sakellari I, Kimiskidis $\mathrm{V}$ et al. Autologous stem cell transplantation in progressive multiple sclerosis-an interim analysis of efficacy. J Clin Immunol 2000; 20: 24-30.

21 Kozák T, Havrdová E, Pit'ha J, Gregora E, Pytlik R, Maaloufova $\mathbf{J}$ et al. High-dose immunosuppressive therapy with PBPC support in the treatment of poor risk multiple sclerosis. Bone Marrow Transplant 2000; 25: 525-531.

22 Burt RK, Oyama Y, Traynor A, Quigley K, Brush M, Rodriguez $\mathrm{J}$ et al. Hematopoietic stem cell transplantation for systemic sclerosis with rapid improvement in skin scores: is neoangiogenesis occurring? Bone Marrow Transplant 2003; 32(Suppl 1): S65-S67.

23 Nash RA, Bowen JD, McSweeney PA, Pavletic SZ, Maravilla KR, Park MS et al. High-dose immunosuppressive therapy and autologous peripheral blood stem cell transplantation for severe multiple sclerosis. Blood 2003; 102: 2364-2372.

24 Carreras E, Saiz A, Marín P, Martinez C, Rovira M, Villamor $\mathrm{N}$ et al. CD34+ selected autologous peripheral blood stem cell transplantation for multiple sclerosis: report of toxicity and treatment results at one year of follow-up in 15 patients. Haematologica 2003; 88: 306-314.

25 Saccardi R, Mancardi GL, Solari A, Bosi A, Bruzzi P, Di Bartolomeo $\mathrm{P}$ et al. Autologous HSCT for severe progressive multiple sclerosis in a multicenter trial: impact on disease activity and quality of life. Blood 2005; 105: 2601-2607.

26 Samijn JPA, te Boekhorst PAW, Mondria T, van Doorn PA, Flach HZ, van der Meché FG et al. Intense T cell depletion followed by autologous bone marrow transplantation for severe multiple sclerosis. J Neurol Neurosurg Psychiatr 2006; 77: 46-50.

27 Burt RK, Loh Y, Cohen B, Stefoski D, Balabanov R, Katsamakis $\mathrm{G}$ et al. Autologous non-myeloablative haemopoietic stem cell transplantation in relapsing-remitting multiple sclerosis: a phase I/II study. Lancet Neurol 2009; 8: 244-253.

28 McSweeney PA, Nash RA, Sullivan KM, Storek J, Crofford LJ, Dansey R et al. High-dose immunosuppressive therapy for severe systemic sclerosis: initial outcomes. Blood 2002; 100: $1602-1610$. 
29 Nash RA, McSweeney PA, Crofford LJ, Abidi M, Chen CS, Godwin JD et al. High-dose immunosuppressive therapy and autologous hematopoietic cell transplantation for severe systemic sclerosis: long-term follow-up of the US multicenter pilot study. Blood 2007; 110: 1388-1396.

30 Oyama Y, Barr WG, Statkute L, Corbridge T, Gonda EA, Jovanovic B et al. Autologous non-myeloablative hematopoietic stem cell transplantation in patients with systemic sclerosis. Bone Marrow Transplant 2007; 40: 549-555.

31 Vonk MC, Marjanovic Z, van den Hoogen FHJ, Zohar S, Schattenberg AV, Fibbe WE et al. Long-term follow-up results after autologous haematopoietic stem cell transplantation for severe systemic sclerosis. Ann Rheum Dis 2008; 67: 98-104.

32 Snowden JA, Biggs JC, Milliken ST, Fuller A, Brooks PM. A phase I/II dose escalation study of intensified cyclophosphamide and autologous blood stem cell rescue in severe, active rheumatoid arthritis. Arthritis Rheum 1999; 42: 2286-2292.

33 Verburg RJ, Mahabali SD, Stiggelbout AM, Sont JK, van Laar JM. High dose chemotherapy and hematopoietic stem cell transplantation: a study of treatment preference in patients with rheumatoid arthritis and rheumatologists. J Rheumatol 2002; 29: 1653-1658.

34 Moore J, Brooks P, Milliken S, Biggs J, Ma D, Handel M et al. A pilot randomized trial comparing CD34-selected versus unmanipulated hemopoietic stem cell transplantation for severe, refractory rheumatoid arthritis. Arthritis Rheum 2002; 46: 2301-2309.

35 Wulffraat N, van Royen A, Bierings M, Vossen J, Kuis W. Autologous haemopoietic stem-cell transplantation in four patients with refractory juvenile chronic arthritis. Lancet 1999; 353: 550-553.

36 Brinkman DMC, de Kleer IM, ten Cate R, van Rossum MA, Bekkering WP, Fasth A et al. Autologous stem cell transplantation in children with severe progressive systemic or polyarticular juvenile idiopathic arthritis: long-term follow-up of a prospective clinical trial. Arthritis Rheum 2007; 56: 2410-2421.

37 Abinun M, Flood TJ, Cant AJ, Veys P, Gennery AR, Foster HE et al. Autologous T cell depleted haematopoietic stem cell transplantation in children with severe juvenile idiopathic arthritis in the UK (2000-2007). Mol Immunol 2009; 47: 46-51.

38 Oyama Y, Craig RM, Traynor AE, Quigley K, Statkute L, Halverson A et al. Autologous hematopoietic stem cell transplantation in patients with refractory Crohn's disease. Gastroenterology 2005; 128: 552-563.

39 Cassinotti A, Annaloro C, Ardizzone S, Onida F, Della Volpe A, Clerici M et al. Autologous haematopoietic stem cell transplantation without CD34 + cell selection in refractory Crohn's disease. Gut 2008; 57: 211-217.

40 Burt RK, Craig RM, Milanetti F, Quigley K, Gozdziak P, Bucha $\mathrm{J}$ et al. Autologous nonmyeloablative hematopoietic stem cell transplantation in patients with severe anti-TNF refractory Crohn disease: long-term follow-up. Blood 2010; 116: 6123-6132.

41 Voltarelli JC, Couri CEB, Stracieri ABPL, Oliveira MC, Moraes DA, Pieroni $\mathrm{F}$ et al. Autologous nonmyeloablative hematopoietic stem cell transplantation in newly diagnosed type 1 diabetes mellitus. JAMA 2007; 297: 1568-1576.

42 Couri CEB, Oliveira MCB, Stracieri ABPL, Moraes DA, Pieroni F, Barros GM et al. C-peptide levels and insulin independence following autologous nonmyeloablative hematopoietic stem cell transplantation in newly diagnosed type 1 diabetes mellitus. JAMA 2009; 301: 1573-1579.
43 Snarski E, Milczarczyk A, Franek E, Jedrzejczak W. Potential role of immunoablation and hematopoietic cell transplantation in the treatment of early diabetes type 1 . Ann Transplant 2010; 15: 75-79.

44 Daikeler T, Hügle T, Farge D, Andolina M, Gualandi F, Baldomero $\mathrm{H}$ et al. Allogeneic hematopoietic SCT for patients with autoimmune diseases. Bone Marrow Transplant 2009; 44: 27-33.

45 Binks M, Passweg JR, Furst D, McSweeney P, Sullivan K, Besenthal $\mathrm{C}$ et al. Phase I/II trial of autologous stem cell transplantation in systemic sclerosis: procedure related mortality and impact on skin disease. Ann Rheum Dis 2001; 60: $577-584$.

46 Fassas A, Passweg JR, Anagnostopoulos A, Kazis A, Kozak $\mathrm{T}$, Havrdova $\mathrm{E}$ et al. Hematopoietic stem cell transplantation for multiple sclerosis. A retrospective multicenter study. J Neurol 2002; 249: 1088-1097.

47 De Kleer IM, Brinkman DMC, Ferster A, Abinun M, Quartier P, van der Net JJ et al. Autologous stem cell transplantation for refractory juvenile idiopathic arthritis: analysis of clinical effects, mortality, and transplant related morbidity. Ann Rheum Dis 2004; 63: 1318-1326.

48 Farge D, Passweg J, van Laar JM, Marjanovic Z, Besenthal $\mathrm{C}$, Finke $\mathrm{J}$ et al. Autologous stem cell transplantation in the treatment of systemic sclerosis: report from the EBMT/ EULAR registry. Ann Rheum Dis 2004; 63: 974-981.

49 Jayne D, Passweg J, Marmont A, Farge D, Zhao X, Arnold $\mathrm{R}$ et al. Autologous stem cell transplantation for systemic lupus erythematosus. Lupus 2004; 13: 168-176.

50 Snowden JA, Passweg J, Moore JJ, Milliken S, Cannell P, van Laar $\mathbf{J}$ et al. Autologous hemopoietic stem cell transplantation in severe rheumatoid arthritis: a report from the EBMT and ABMTR. J Rheumatol 2004; 31: 482-488.

51 Passweg JR, Rabusin M, Musso M, Beguin Y, Cesaro S, Ehninger $\mathrm{G}$ et al. Haematopoetic stem cell transplantation for refractory autoimmune cytopenia. Br J Haematol 2004; 125 : $749-755$.

52 Saccardi R, Kozak T, Bocelli-Tyndall C, Fassas A, Kazis A, Havrdova E et al. Autologous stem cell transplantation for progressive multiple sclerosis: update of the European Group for Blood and Marrow Transplantation autoimmune diseases working party database. Mult Scler 2006; 12: 814-823.

53 Daikeler T, Kötter I, Bocelli Tyndall C, Apperley J, Attarbaschi A, Guardiola P et al. Haematopoietic stem cell transplantation for vasculitis including Behcet's disease and polychondritis: a retrospective analysis of patients recorded in the European Bone Marrow Transplantation and European League Against Rheumatism databases and a review of the literature. Ann Rheum Dis 2007; 66: 202-207.

54 Rabusin M. Haematpoietic stem cell transplantation in severe autoimmune diseases in children. Results and new perspectives. Bone Marrow Transplant 2010; 45: 1:S6-1:S7.

55 Radbruch A, Thiel A. Cell therapy for autoimmune diseases: does it have a future? Ann Rheum Dis 2004; 63(Suppl 2): ii96-ii101.

56 Hinterberger W, Hinterberger-Fischer M, Marmont A. Clinically demonstrable anti-autoimmunity mediated by allogeneic immune cells favorably affects outcome after stem cell transplantation in human autoimmune diseases. Bone Marrow Transplant 2002; 30: 753-759.

57 Marmont AM, Gualandi F, Van Lint MT, Bacigalupo A. Refractory Evans' syndrome treated with allogeneic SCT followed by DLI. Demonstration of a graft-versus-autoimmunity effect. Bone Marrow Transplant 2003; 31: 399-402.

58 Hough RE, Snowden JA, Wulffraat NM. Haemopoietic stem cell transplantation in autoimmune diseases: a European perspective. Br J Haematol 2005; 128: 432-459. 
59 Griffith LM, Pavletic SZ, Tyndall A, Bredeson CN, Bowen JD, Childs RW et al. Feasibility of allogeneic hematopoietic stem cell transplantation for autoimmune disease: position statement from a National Institute of Allergy and Infectious Diseases and National Cancer Institute-Sponsored International Workshop, Bethesda, MD, March 12 and 13, 2005. Biol Blood Marrow Transplant 2005; 11: 862-870.

60 Marmont AM, Dominietto A, Gualandi F, Piaggio G, van Lint MT, Bacigalupo A. Pure white cell aplasia (PWCA) relapsing after allogeneic BMT and successfully treated with nine DLIs. Biol Blood Marrow Transplant 2006; 12: 987-989.

61 Muraro PA, Douek DC, Packer A, Chung K, Guenaga FJ, Cassiani-Ingoni $\mathrm{R}$ et al. Thymic output generates a new and diverse TCR repertoire after autologous stem cell transplantation in multiple sclerosis patients. J Exp Med 2005; 201: $805-816$.

62 Farge D, Henegar C, Carmagnat M, Daneshpouy M, Marjanovic Z, Rabian C et al. Analysis of immune reconstitution after autologous bone marrow transplantation in systemic sclerosis. Arthritis Rheum 2005; 52: 1555-1563.

63 de Kleer I, Vastert B, Klein M, Teklenburg G, Arkesteijn G, Yung GP et al. Autologous stem cell transplantation for autoimmunity induces immunologic self-tolerance by reprogramming autoreactive $\mathrm{T}$ cells and restoring the CD4 + CD25 + immune regulatory network. Blood 2006; 107: $1696-1702$.

64 Roord STA, de Jager W, Boon L, Wulffraat N, Martens A, Prakken B et al. Autologous bone marrow transplantation in autoimmune arthritis restores immune homeostasis through CD4 + CD25 + Foxp3 + regulatory T cells. Blood 2008; 111: $5233-5241$

65 van Wijk F, Roord ST, Vastert B, de Kleer I, Wulffraat N, Prakken BJ. Regulatory $\mathrm{T}$ cells in autologous stem cell transplantation for autoimmune disease. Autoimmunity 2008; 41: $585-591$.

66 Alexander T, Thiel A, Rosen O, Massenkeil G, Sattler A, Kohler $\mathrm{S}$ et al. Depletion of autoreactive immunologic memory followed by autologous hematopoietic stem cell transplantation in patients with refractory SLE induces longterm remission through de novo generation of a juvenile and tolerant immune system. Blood 2009; 113: 214-223.

67 Zhang L, Bertucci AM, Ramsey-Goldman R, Burt RK, Datta SK. Regulatory T cell (Treg) subsets return in patients with refractory lupus following stem cell transplantation, and TGF-beta-producing CD8 + Treg cells are associated with immunological remission of lupus. J Immunol 2009; 183: 6346-6358.

68 Bingham S, Veale D, Fearon U, Isaacs JD, Morgan G, Emery $\mathrm{P}$ et al. High-dose cyclophosphamide with stem cell rescue for severe rheumatoid arthritis: short-term efficacy correlates with reduction of macroscopic and histologic synovitis. Arthritis Rheum 2002; 46: 837-839.

69 Muraro P. Restoring self-tolerance: lessons from the clinic. Bone Marrow Transplant 2010; 45: 1:S2.

70 Verrecchia F, Laboureau J, Verola O, Roos N, Porcher R, Bruneval $\mathrm{P}$ et al. Skin involvement in scleroderma-where histological and clinical scores meet. Rheumatology (Oxford) 2007; 46: 833-841.

71 Farge D, Nash R, Laar JM. Autologous stem cell transplantation for systemic sclerosis. Autoimmunity 2008; 41: 616-624.

72 Fleming JN, Nash RA, McLeod DO, Fiorentino DF, Shulman HM, Connolly MK et al. Capillary regeneration in scleroderma: stem cell therapy reverses phenotype? PLoS One 2008; 3: e1452.

73 Miniati I, Guiducci S, Conforti ML, Rogai V, Fiori G, Cinelli $\mathrm{M}$ et al. Autologous stem cell transplantation improves microcirculation in systemic sclerosis. Ann Rheum Dis 2009; 68: 94-98.

74 Launay D, Marjanovic Z, de Bazelaire C, Florea L, Zohar S, Keshtmand $\mathrm{H}$ et al. Autologous hematopoietic stem cell transplant in systemic sclerosis: quantitative high resolution computed tomography of the chest scoring. J Rheumatol 2009; 36: 1460-1463.

75 Loh Y, Oyama Y, Statkute L, Quigley K, Yaung K, Gonda E et al. Development of a secondary autoimmune disorder after hematopoietic stem cell transplantation for autoimmune diseases: role of conditioning regimen used. Blood 2007; 109: 2643-2548.

76 Daikeler T, Labopin M, Di Gioia M, Abinun M, Alexander $\mathrm{T}$, Miniati I et al. Secondary autoimmune diseases occuring after stem cell transplantation for an autoimmune disease: a retrospective study of the European Group for Blood \& Marrow Transplantation Autoimmune Diseases Working Party. Blood 2011; 118: 1693-1698.

77 Tailor IK, Akil M, Rennie I, Ross RJ, Snowden JA. Reconstitution Graves' disease following autologous haematopoietic stem cell transplantation (HSCT) for severe diffuse systemic sclerosis. $Q J$ Med 2011; (e-pub ahead of print 30 March 2011).

78 Ljungman P, Bregni M, Brune M, Cornelissen J, de Witte T, Dini $\mathrm{G}$ et al. Allogeneic and autologous transplantation for haematological diseases, solid tumours and immune disorders: current practice in Europe 2009. Bone Marrow Transplant 2010; 45: 219-234.

79 Gratwohl A, Brand R, Niederwieser D, Baldomero H, Chabannon $\mathrm{C}$, Cornelissen $\mathrm{J}$ et al. Introduction of a quality management system and outcome after hematopoietic stemcell transplantation. J Clin Oncol 2011; 29: 1980-1986.

80 Chabannon C, Pamphilon D, Vermylen C, Gratwohl A, Niederwieser D, McGrath E et al. Ten years after the first inspection of a candidate European centre, an EBMT registry analysis suggests that clinical outcome is improved when hematopoietic SCT is performed in a JACIE accredited program. Bone Marrow Transplant 2011 (e-pub ahead of print 7 March 2011). Available at: http://wwwncbi.nlm.nih.gov/ pubmed/21383685 (Consulté avril 20, 2011).

81 Popat U, Krance R. Haematopoietic stem cell transplantation for autoimmune disorders: the American perspective. $\mathrm{Br}$ J Haematol 2004; 126: 637-649.

82 Illei GG. Hematopoietic stem cell transplantation in autoimmune diseases: is the glass half full or half empty? Arthritis Rheum 2006; 54: 3730-3734.

83 Kapoor S, Wilson AG, Sharrack B, Lobo A, Akil M, Sun L et al. Haemopoietic stem cell transplantation - an evolving treatment for severe autoimmune and inflammatory diseases in rheumatology, neurology and gastroenterology. Hematology 2007; 12: 179-191.

84 Rabusin M, Andolina M, Maximova N. Haematopoietic SCT in autoimmune diseases in children: rationale and new perspectives. Bone Marrow Transplant 2008; 41(Suppl 2): S96-S99.

85 Krauss AC, Kamani NR. Hematopoietic stem cell transplantation for pediatric autoimmune disease: where we stand and where we need to go. Bone Marrow Transplant 2009; 44: 137-143.

86 Burt RK, Loh Y, Pearce W, Beohar N, Barr WG, Craig R et al. Clinical applications of blood-derived and marrowderived stem cells for nonmalignant diseases. JAMA 2008; 299: 925-936.

87 Sullivan KM, Muraro P, Tyndall A. Hematopoietic cell transplantation for autoimmune disease: updates from Europe and the United States. Biol Blood Marrow Transplant 2010; 16(Suppl): S48-S56. 
88 Kurtzke JF. Rating neurologic impairment in multiple sclerosis: an expanded disability status scale (EDSS). Neurology 1983; 33: 1444-1452.

89 Isenberg DA, Gordon C. From BILAG to BLIPS - disease activity assessment in lupus past, present and future. Lupus 2000; 9: 651-654.

90 Bombardier C, Gladman DD, Urowitz MB, Caron D, Chang $\mathrm{CH}$. Derivation of the SLEDAI. A disease activity index for lupus patients. The Committee on Prognosis Studies in SLE. Arthritis Rheum 1992; 35: 630-640.

91 Verburg RJ, Sont JK, Vliet Vlieland TP, Landewé RB, Boers $\mathbf{M}$, Kievit $\mathbf{J}$ et al. High dose chemotherapy followed by autologous peripheral blood stem cell transplantation or conventional pharmacological treatment for refractory rheumatoid arthritis? A Markov decision analysis. J Rheumatol 2001; 28: 719-727.

92 Tappenden P, Saccardi R, Confavreux C, Sharrack B, Muraro PA, Mancardi GL et al. Autologous haematopoietic stem cell transplantation for secondary progressive multiple sclerosis: an exploratory cost-effectiveness analysis. Bone Marrow Transplant 2010; 45: 1014-1021.

93 Atkins H. Hematopoietic SCT for the treatment of multiple sclerosis. Bone Marrow Transplant 2010; 45: 1671-1681.

94 Snowden JA, Biggs JC, Milliken ST, Fuller A, Staniforth D, Passuello F et al. A randomised, blinded, placebo-controlled, dose escalation study of the tolerability and efficacy of filgrastim for haemopoietic stem cell mobilisation in patients with severe active rheumatoid arthritis. Bone Marrow Transplant 1998; 22: 1035-1041.

95 Openshaw H, Stuve O, Antel JP, Nash R, Lund BT, Weiner LP et al. Multiple sclerosis flares associated with recombinant granulocyte colony-stimulating factor. Neurology 2000; 54: 2147-2150.

96 Burt RK, Fassas A, Snowden J, van Laar JM, Kozak T, Wulffraat NM et al. Collection of hematopoietic stem cells from patients with autoimmune diseases. Bone Marrow Transplant 2001; 28: 1-12.

97 Statkute L, Verda L, Oyama Y, Traynor A, Villa M, Shook T et al. Mobilization, harvesting and selection of peripheral blood stem cells in patients with autoimmune diseases undergoing autologous hematopoietic stem cell transplantation. Bone Marrow Transplant 2007; 39: 317-329.

98 Zhang W, Zhou D-B, Zhao Y, Zhuang JL, Leng XM, Wang SJ et al. Peripheral blood CD34+ cell mobilization in 42 patients with severe autoimmune disease. Chin Med Sci J 2007; 22: 108-112.

99 Saccardi R, Tyndall A, Coghlan G, Denton C, Edan G, Emdin $\mathrm{M}$ et al. Consensus statement concerning cardiotoxicity occurring during haematopoietic stem cell transplantation in the treatment of autoimmune diseases, with special reference to systemic sclerosis and multiple sclerosis. Bone Marrow Transplant 2004; 34: 877-881.

100 Wulffraat NM, van Rooijen EM, Tewarie R, Brinkman D, Prakken B, Kuis W. Current perspectives of autologous stem cell transplantation for severe juvenile idiopathic arthritis. Autoimmunity 2008; 41: 632-638.

101 Martino R, Sureda A, Brunet S. Peripheral blood stem cell mobilization in refractory autoimmune Evans syndrome: a cautionary case report. Bone Marrow Transplant 1997; 20: 521 .

102 Kreisel W, Potthoff K, Bertz H, Schmitt-Graeff A, Ruf G, Rasenack J et al. Complete remission of Crohn's disease after high-dose cyclophosphamide and autologous stem cell transplantation. Bone Marrow Transplant 2003; 32: 337-340.

103 Rovira M, Ricart E, Feu F, Pino S, Comas D, FernandezAviles $\mathrm{F}$ et al. Infectious complications during the mobiliza- tion phase in patients with refractory Crohn's disease suitable for autologous stem cell transplantation. Bone Marrow Transplant 2011; 46(Suppl 1): S377-S378.

104 Tyndall A, Gratwohl A. Blood and marrow stem cell transplants in autoimmune disease. A consensus report written on behalf of the European League Against Rheumatism (EULAR) and the European Group for Blood and Marrow Transplantation (EBMT). Br J Rheumatol 1997; 36: 390-392.

105 Bakker B, Massa GG, Oostdijk W, Van Weel-Sipman MH, Vossen JM, Wit JM. Pubertal development and growth after total-body irradiation and bone marrow transplantation for haematological malignancies. Eur J Pediatr 2000; 159: 31-37.

106 Burt RK, Cohen BA, Russell E, Spero K, Joshi A, Oyama Y et al. Hematopoietic stem cell transplantation for progressive multiple sclerosis: failure of a total body irradiationbased conditioning regimen to prevent disease progression in patients with high disability scores. Blood 2003; 102: 2373-2378.

107 Burt RK, Patel D, Thomas J, Yeager A, Traynor A, Heipe F et al. The rationale behind autologous autoimmune hematopoietic stem cell transplant conditioning regimens: concerns over the use of total-body irradiation in systemic sclerosis. Bone Marrow Transplant 2004; 34: 745-751.

108 Ferry C, Gemayel G, Rocha V, Labopin M, Esperou H, Robin $\mathrm{M}$ et al. Long-term outcomes after allogeneic stem cell transplantation for children with hematological malignancies. Bone Marrow Transplant 2007; 40: 219-224.

109 Eiser C, Absolom K, Greenfield D, Snowden J, Coleman R, Hancock B et al. Follow-up care for young adult survivors of cancer: lessons from pediatrics. J Cancer Surviv 2007; 1: 75-86.

110 Burt RK, Abinun M, Farge-Bancel D, Fassas A, Hiepe F, Havrdová E et al. Risks of immune system treatments. Science 2010; 328: 825-826.

111 Morris ES, Sharrack B, Dalley CD, Snowden JA. The Uhthoff phenomenon: a potential post transplant complication in advanced progressive multiple sclerosis. Bone Marrow Transplant 2007; 40: 1003-1004.

112 Nash RA, Dansey R, Storek J, Georges GE, Bowen JD, Holmberg LA et al. Epstein-Barr virus-associated posttransplantation lymphoproliferative disorder after high-dose immunosuppressive therapy and autologous CD34-selected hematopoietic stem cell transplantation for severe autoimmune diseases. Biol Blood Marrow Transplant 2003; 9: 583-591.

113 Leng XM, Zhao Y, Zhou DB, Situ H, Li TS, Shen T et al. A pilot trial for severe, refractory systemic autoimmune disease with stem cell transplantation. Chin Med Sci J 2005; 20: $159-165$.

114 Oyama Y, Cohen B, Traynor A, Brush M, Rodriguez J, Burt RK. Engraftment syndrome: a common cause for rash and fever following autologous hematopoietic stem cell transplantation for multiple sclerosis. Bone Marrow Transplant 2002; 29: 81-85.

115 Carreras E, Fernández-Avilés F, Silva L, Guerrero M, Fernández de Larrea C, Martínez $\mathrm{C}$ et al. Engraftment syndrome after auto-SCT: analysis of diagnostic criteria and risk factors in a large series from a single center. Bone Marrow Transplant 2010; 45: 1417-1422.

116 Tyndall AJ, Joly F, Carbonne B, Deligny CN, Farge DC. Pregnancy and childbirth after treatment with autologous hematopoietic stem cell transplantation for severe systemic sclerosis requiring parenteral nutrition. Ethical issues. Clin Exp Rheumatol 2008; 26: 1122-1124.

117 Compston A, Coles A. Multiple sclerosis. Lancet 2008; 372: $1502-1517$ 
118 Johnson KP, Brooks BR, Cohen JA, Ford CC, Goldstein J, Lisak RP et al. Copolymer 1 reduces relapse rate and improves disability in relapsing-remitting multiple sclerosis: results of a phase III multicenter, double-blind placebocontrolled trial. The Copolymer 1 Multiple Sclerosis Study Group. Neurology 1995; 45: 1268-1276.

119 Paty DW, Li DK. Interferon beta-1b is effective in relapsingremitting multiple sclerosis. II. MRI analysis results of a multicenter, randomized, double-blind, placebo-controlled trial. UBC MS/MRI Study Group and the IFNB Multiple Sclerosis Study Group. Neurology 1993; 43: 662-667.

120 Cohen JA, Barkhof F, Comi G, Hartung HP, Khatri BO, Montalban $\mathrm{X}$ et al. Oral fingolimod or intramuscular interferon for relapsing multiple sclerosis. $N$ Engl $J$ Med 2010; 362: 402-415.

121 Edan G, Miller D, Clanet M, Confavreux C, Lyon-Caen O, Lubetzki $\mathrm{C}$ et al. Therapeutic effect of mitoxantrone combined with methylprednisolone in multiple sclerosis: a randomised multicentre study of active disease using MRI and clinical criteria. J Neurol Neurosurg Psychiatr 1997; 62: $112-118$.

122 Miller DH, Khan OA, Sheremata WA, Blumhardt LD, Rice GP, Libonati MA et al. A controlled trial of natalizumab for relapsing multiple sclerosis. $N$ Engl $J$ Med 2003; 348: 15-23.

123 Marriott JJ, Miyasaki JM, Gronseth G, O'Connor PW. Evidence Report: the efficacy and safety of mitoxantrone (Novantrone) in the treatment of multiple sclerosis: Report of the Therapeutics and Technology Assessment Subcommittee of the American Academy of Neurology. Neurology 2010; 74 $1463-1470$.

124 Saiz A, Blanco Y, Carreras E, Berenguer J, Rovira M, Pujol $\mathrm{T}$ et al. Clinical and MRI outcome after autologous hematopoietic stem cell transplantation in MS. Neurology 2004; 62: 282-284.

125 Mancardi GL, Murialdo A, Rossi P, Gualandi F, Martino G, Marmont A et al. Autologous stem cell transplantation as rescue therapy in malignant forms of multiple sclerosis. Mult Scler 2005; 11: 367-371.

126 Krasulová E, Trneny M, Kozák T, Vacková B, Pohlreich D, Kemlink D et al. High-dose immunoablation with autologous haematopoietic stem cell transplantation in aggressive multiple sclerosis: a single centre 10-year experience. Mult Scler 2010; 16: 685-693.

127 Hamerschlak N, Rodrigues M, Moraes DA, Oliveira MC, Stracieri AB, Pieroni $\mathrm{F}$ et al. Brazilian experience with two conditioning regimens in patients with multiple sclerosis: BEAM/horse ATG and CY/rabbit ATG. Bone Marrow Transplant 2010; 45: 239-248.

$128 \mathrm{Xu} \mathrm{J}$, Ji B-X, Su L, Dong HQ, Sun WL, Wan SG et al. Clinical outcome of autologous peripheral blood stem cell transplantation in opticospinal and conventional forms of secondary progressive multiple sclerosis in a Chinese population. Ann Hematol 2011; 90: 343-348.

129 Freedman M, Amato M, Atkins H, Carreras E, Fassas A, Griffith LM et al. Panel session report: multiples sclerosis. Bone Marrow Transplant 2010; 45: 1:S8-1:10.

130 Fassas A, Kimiskidis VK, Sakellari I, Kapinas K, Anagnostopoulos A, Tsimourtou $\mathrm{V}$ et al. Long-term results of stem cell transplantation for MS: a single-center experience. Neurology 2011; 76: 1066-1070.

131 Gabrielli A, Avvedimento EV, Krieg T. Scleroderma. $N$ Engl J Med 2009; 360: 1989-2003.

132 Ferri C, Valentini G, Cozzi F, Sebastiani M, Michelassi C, La Montagna $\mathrm{G}$ et al. Systemic sclerosis: demographic, clinical, and serologic features and survival in 1,012 Italian patients. Medicine (Baltimore) 2002; 81: 139-153.
133 Abraham DJ, Varga J. Scleroderma: from cell and molecular mechanisms to disease models. Trends Immunol 2005; 26: 587-595.

134 Nihtyanova SI, Tang EC, Coghlan JG, Wells AU, Black CM, Denton CP. Improved survival in systemic sclerosis is associated with better ascertainment of internal organ disease: a retrospective cohort study. $Q$ J Med 2010; 103: 109-115.

135 Domsic RT, Rodriguez-Reyna T, Lucas M, Fertig N, Medsger Jr TA. Skin thickness progression rate: a predictor of mortality and early internal organ involvement in diffuse scleroderma. Ann Rheum Dis 2011; 70: 104-109.

136 Ioannidis JPA, Vlachoyiannopoulos PG, Haidich A-B, Medsger Jr TA, Lucas M, Michet CJ et al. Mortality in systemic sclerosis: an international meta-analysis of individual patient data. Am J Med 2005; 118: 2-10.

137 Scussel-Lonzetti L, Joyal F, Raynauld J-P, Roussin A, Rich E, Goulet JR et al. Predicting mortality in systemic sclerosis: analysis of a cohort of 309 French Canadian patients with emphasis on features at diagnosis as predictive factors for survival. Medicine (Baltimore) 2002; 81: 154-167.

138 Tashkin DP, Elashoff R, Clements PJ, Goldin J, Roth MD, Furst DE et al. Cyclophosphamide versus placebo in scleroderma lung disease. N Engl J Med 2006; 354: 2655-2666.

139 Nannini C, West CP, Erwin PJ, Matteson EL. Effects of cyclophosphamide on pulmonary function in patients with scleroderma and interstitial lung disease: a systematic review and meta-analysis of randomized controlled trials and observational prospective cohort studies. Arthritis Res Ther 2008; 10: R124.

140 Farge D, Marolleau JP, Zohar S, Marjanovic Z, Cabane J, Mounier $\mathrm{N}$ et al. Autologous bone marrow transplantation in the treatment of refractory systemic sclerosis: early results from a French multicentre phase I-II study. Br J Haematol 2002; 119: 726-739.

141 Martini G, Foeldvari I, Russo R, Cuttica R, Eberhard A, Ravelli A et al. Systemic sclerosis in childhood: clinical and immunologic features of 153 patients in an international database. Arthritis Rheum 2006; 54: 3971-3978.

142 Sutcliffe N, Clarke AE, Gordon C, Farewell V, Isenberg DA. The association of socio-economic status, race, psychosocial factors and outcome in patients with systemic lupus erythematosus. Rheumatology (Oxford) 1999; 38: 1130-1137.

143 Cervera R, Khamashta MA, Font J, Sebastiani GD, Gil A, Lavilla $\mathrm{P}$ et al. Morbidity and mortality in systemic lupus erythematosus during a 10-year period: a comparison of early and late manifestations in a cohort of 1000 patients. Medicine (Baltimore) 2003; 82: 299-308.

144 Cervera R, Khamashta MA, Hughes GRV. The Euro-lupus project: epidemiology of systemic lupus erythematosus in Europe. Lupus 2009; 18: 869-874.

145 Fiehn C, Hajjar Y, Mueller K, Waldherr R, Ho AD, Andrassy K. Improved clinical outcome of lupus nephritis during the past decade: importance of early diagnosis and treatment. Ann Rheum Dis 2003; 62: 435-439.

146 Illei GG, Austin HA, Crane M, Collins L, Gourley MF, Yarboro $\mathrm{CH}$ et al. Combination therapy with pulse cyclophosphamide plus pulse methylprednisolone improves long-term renal outcome without adding toxicity in patients with lupus nephritis. Ann Intern Med 2001; 135: 248-257.

147 Contreras G, Pardo V, Leclercq B, Lenz O, Tozman E, O'Nan $\mathrm{P}$ et al. Sequential therapies for proliferative lupus nephritis. $N$ Engl J Med 2004; 350: 971-980.

148 Houssiau FA, Vasconcelos C, D'Cruz D, Sebastiani GD, Garrido Ed Ede R, Danieli MG et al. Immunosuppressive therapy in lupus nephritis: the Euro-Lupus Nephritis Trial, a randomized trial of low-dose versus high-dose intravenous cyclophosphamide. Arthritis Rheum 2002; 46: 2121-2131. 
149 Gayed M, Gordon C. Novel treatments for systemic lupus erythematosus. Curr Opin Invest Drugs 2010; 11: 1256-1264.

150 Nossent J, Cikes N, Kiss E, Marchesoni A, Nassonova V, Mosca $\mathrm{M}$ et al. Current causes of death in systemic lupus erythematosus in Europe, 2000-2004: relation to disease activity and damage accrual. Lupus 2007; 16: 309-317.

151 Doria A, Iaccarino L, Ghirardello A, Zampieri S, Arienti S, Sarzi-Puttini $\mathrm{P}$ et al. Long-term prognosis and causes of death in systemic lupus erythematosus. Am J Med 2006; 119: 700-706.

152 Houssiau FA, Vasconcelos C, D'Cruz D, Sebastiani GD, de Ramon Garrido E, Danieli MG et al. The 10-year follow-up data of the Euro-Lupus Nephritis Trial comparing low-dose and high-dose intravenous cyclophosphamide. Ann Rheum Dis 2010; 69: 61-64.

153 Burt RK, Traynor A, Statkute L, Barr WG, Rosa R, Schroeder $\mathbf{J}$ et al. Nonmyeloablative hematopoietic stem cell transplantation for systemic lupus erythematosus. JAMA 2006; 295: 527-535.

154 Alexander T, Biesen R, Jacobi A, Hoyer B, Bruns A, Hiepe F. Systemic lupus erythematosus. Target criteria for treatment. Z Rheumatol 2009; 68: 23-29.

155 Shanahan F. Crohn's disease. Lancet 2002; 359: 62-69.

156 Cosgrove M, Al-Atia RF, Jenkins HR. The epidemiology of paediatric inflammatory bowel disease. Arch Dis Child 1996; 74: 460-461.

157 Hampe J, Cuthbert A, Croucher PJ, Mirza MM, Mascheretti $\mathrm{S}$, Fisher $\mathrm{S}$ et al. Association between insertion mutation in NOD2 gene and Crohn's disease in German and British populations. Lancet 2001; 357: 1925-1928.

158 Jess T, Riis L, Jespersgaard C, Hougs L, Andersen PS, Orholm MK et al. Disease concordance, zygosity, and NOD2/CARD15 status: follow-up of a population-based cohort of Danish twins with inflammatory bowel disease. Am $J$ Gastroenterol 2005; 100: 2486-2492.

159 Nash RA, McDonald GB. Crohn disease: remissions but no cure. Blood 2010; 116: 5790-5791.

160 Anon. Guidelines for the investigation and management of idiopathic thrombocytopenic purpura in adults, children and in pregnancy. $B r J$ Haematol 2003; 120: 574-596.

161 Provan D, Stasi R, Newland AC, Blanchette VS, BoltonMaggs P, Bussel JB et al. International consensus report on the investigation and management of primary immune thrombocytopenia. Blood 2010; 115: 168-186.

162 Rose N, Mackay I. The Autoimmune Disease, 4th edn. Elsevier Academic Press: San Diego, CA, 2006.

163 Norton A, Roberts I. Management of Evans syndrome. $\mathrm{Br} \mathrm{J}$ Haematol 2006; 132: 125-137.

164 Passweg J, Storek J, Biletti C, Guanlandi F, Rabusin M. Panel session report: autoimmune cytopenias. Bone Marrow Transplant 2010; 45: 1:S14.

165 Huhn RD, Fogarty PF, Nakamura R, Read EJ, Leitman SF, Rick ME et al. High-dose cyclophosphamide with autologous lymphocyte-depleted peripheral blood stem cell (PBSC) support for treatment of refractory chronic autoimmune thrombocytopenia. Blood 2003; 101: 71-77.

166 Quartier P, Taupin P, Bourdeaut F, Lemelle I, Pillet P, Bost $\mathrm{M}$ et al. Efficacy of etanercept for the treatment of juvenile idiopathic arthritis according to the onset type. Arthritis Rheum 2003; 48: 1093-1101.

167 Yokota S, Miyamae T, Imagawa T, Iwata N, Katakura S, Mori $\mathrm{M}$ et al. Therapeutic efficacy of humanized recombinant anti-interleukin-6 receptor antibody in children with systemic-onset juvenile idiopathic arthritis. Arthritis Rheum 2005; 52: 818-825.

168 Verburg RJ, Sont JK, van Laar JM. Reduction of joint damage in severe rheumatoid arthritis by high-dose che- motherapy and autologous stem cell transplantation. Arthritis Rheum 2005; 52: 421-424.

169 Teng YKO, Verburg RJ, Sont JK, van den Hout WB, Breedveld FC, van Laar JM. Long-term followup of health status in patients with severe rheumatoid arthritis after high-dose chemotherapy followed by autologous hematopoietic stem cell transplantation. Arthritis Rheum 2005; 52: 2272-2276

170 Snowden JA, Kapoor S, Wilson AG. Stem cell transplantation in rheumatoid arthritis. Autoimmunity 2008; 41: 625-631.

171 Keogh KA, Wylam ME, Stone JH, Specks U. Induction of remission by $\mathrm{B}$ lymphocyte depletion in eleven patients with refractory antineutrophil cytoplasmic antibody-associated vasculitis. Arthritis Rheum 2005; 52: 262-268.

172 Kötter I, Daikeler T, Amberger C, Tyndall A, Kanz L. Autologous stem cell transplantation of treatment-resistant systemic vasculitis - a single center experience and review of the literature. Clin Nephrol 2005; 64: 485-489.

173 Kunitomi A, Ishikawa T, Tajima K, Konaka Y, Yagita M. Bone marrow transplantation with a reduced-intensity conditioning regimen in a patient with Wegener granulomatosis and therapy-related leukemia. Int $J$ Hematol 2006; 83: 262-265.

174 Maurer B, Hensel M, Max R, Fiehn C, Ho AD, Lorenz HM. Autologous haematopoietic stem cell transplantation for Behcet's disease with pulmonary involvement: analysis after 5 years of follow up. Ann Rheum Dis 2006; 65: 127-129.

175 Statkute L, Oyama Y, Barr WG, Sufit R, Ho S, Verda L et al. Autologous non-myeloablative haematopoietic stem cell transplantation for refractory systemic vasculitis. Ann Rheum Dis 2008; 67: 991-997.

176 Bingham S, Griffiths B, McGonagle D, Snowden JA, Morgan G, Emery P. Autologous stem cell transplantation for rapidly progressive Jo-1-positive polymyositis with long-term followup. Br J Haematol 2001; 113: 840-841.

177 Oryoji K, Himeji D, Nagafuji K, Horiuchi T, Tsukamoto H, Gondo $\mathrm{H}$ et al. Successful treatment of rapidly progressive interstitial pneumonia with autologous peripheral blood stem cell transplantation in a patient with dermatomyositis. Clin Rheumatol 2005; 24: 637-640.

178 Tsukamoto H, Nagafuji K, Horiuchi T, Miyamoto T, Aoki $\mathrm{K}$, Takase $\mathrm{K}$ et al. A phase I-II trial of autologous peripheral blood stem cell transplantation in the treatment of refractory autoimmune disease. Ann Rheum Dis 2006; 65: 508-514.

179 Holzer U, van Royen-Kerkhof A, van der Torre $\mathrm{P}$, Kuemmerle-Deschner J, Well C, Handgretinger $\mathrm{R}$ et al. Successful autologous stem cell transplantation in two patients with juvenile dermatomyositis. Scand J Rheumatol 2010; 39: 88-92.

180 Vermeulen M, Van Oers MH. Successful autologous stem cell transplantation in a patient with chronic inflammatory demyelinating polyneuropathy. J Neurol Neurosurg Psychiatr 2002; 72: 127-128.

181 Kazmi MA, Mahdi-Rogers M, Sanvito L. Chronic inflammatory demyelinating polyradiculoneuropathy: a role for haematopoietic stem cell transplantation? Autoimmunity 2008; 41: 611-615.

182 Mahdi-Rogers M, Kazmi M, Ferner R, Hughes RA, Renaud $\mathrm{S}$, Steck AJ et al. Autologous peripheral blood stem cell transplantation for chronic acquired demyelinating neuropathy. J Peripher Nerv Syst 2009; 14: 118-124.

183 Van den Bergh PYK, Hadden RDM, Bouche P, Cornblath DR, Hahn A, Illa I et al. European Federation of Neurological Societies/Peripheral Nerve Society guideline on management of chronic inflammatory demyelinating polyradiculoneuropathy: report of a joint task force of the 
European Federation of Neurological Societies and the Peripheral Nerve Society-first revision. Eur J Neurol 2010; 17: 356-363.

184 Peng F, Qiu W, Li J, Hu X, Huang R, Lin D et al. A preliminary result of treatment of neuromyelitis optica with autologous peripheral hematopoietic stem cell transplantation. Neurologist 2010; 16: 375-378.

185 Matiello M, Pittock SJ, Porrata L, Weinshenker BG. Failure of autologous hematopoietic stem cell transplantation to prevent relapse of neuromyelitis optica. Arch Neurol 2011; 68: 933-935.

186 Epidemiology of Diabetes Interventions and Complications Research Group. The effect of intensive insulin therapy on the microvascular complications of type 1 diabetes mellitus. JAMA 2002; 287: 2563-2569.

187 American Diabetes Association. Diagnosis and classification of diabetes. Diabetes Care 2004; 27 (Suppl I): S5-S10.

188 Pescovitz MD, Greenbaum CJ, Krause-Steinrauf H, Becker DJ, Gitelman SE, Goland R et al. Rituximab, B-lymphocyte depletion, and preservation of beta-cell function. $N$ Engl $J$ Med 2009; 361: 2143-2152.

189 Voltarelli JC, Couri CEB, Stracieri ABPL, Oliveira MC, Moraes DA, Pieroni F et al. Autologous hematopoietic stem cell transplantation for type 1 diabetes. Ann N Y Acad Sci 2008; 1150: 220-229.

190 Hopper AD, Hadjivassiliou M, Butt S, Sanders DS. Adult coeliac disease. $B M J$ 2007; 335: 558-562.

191 Al-toma A, Visser OJ, van Roessel HM, von Blomberg BM, Verbeek WH, Scholten PE et al. Autologous hematopoietic stem cell transplantation in refractory celiac disease with aberrant T cells. Blood 2007; 109: 2243-2249.

192 Tack GJ, Wondergem MJ, Al-Toma A, Verbeek WH, Schmittel A, Machado MV et al. Auto-SCT in refractory celiac disease type II patients unresponsive to cladribine therapy. Bone Marrow Transplant 2010; 46: 840-846.

193 McColl GJ, Szer J, Wicks IP. Sustained remission, possibly cure, of seronegative arthritis after high-dose chemotherapy and syngeneic hematopoietic stem cell transplantation. Arthritis Rheum 2005; 52: 3322.

194 Zaydan MA, Turner C, Miller AM. Resolution of chronic idiopathic thrombocytopenia purpura following syngeneic peripheral blood progenitor transplant. Bone Marrow Transplant 2002; 29: 87-89.

195 van Oosterhout M, Verburg RJ, Levarht EWN, Moolenburgh JD, Barge RM, Fibbe WE et al. High dose chemotherapy and syngeneic stem cell transplantation in a patient with refractory rheumatoid arthritis: poor response associated with persistence of host autoantibodies and synovial abnormalities. Ann Rheum Dis 2005; 64: 1783-1785.
196 Butler JP, Durrant STS, Frost T. Successful remission of chronic, refractory autoimmune thrombocytopenic purpura following non-myeloablative allogeneic stem cell transplantation. Bone Marrow Transplant 2003; 31: 621-622.

197 Burt RK, Oyama Y, Verda L, Quigley K, Brush M, Yaung K et al. Induction of remission of severe and refractory rheumatoid arthritis by allogeneic mixed chimerism. Arthritis Rheum 2004; 50: 2466-2470.

198 Khorshid O, Hosing C, Bibawi S, Ueno N, Reveille J, Mayes MD et al. Nonmyeloablative stem cell transplant in a patient with advanced systemic sclerosis and systemic lupus erythematosus. $J$ Rheumatol 2004; 31: 2513-2516.

199 Nash RA, McSweeney PA, Nelson JL, Wener M, Georges GE, Langston AA et al. Allogeneic marrow transplantation in patients with severe systemic sclerosis: resolution of dermal fibrosis. Arthritis Rheum 2006; 54: 1982-1986.

$200 \mathrm{Lu} \mathrm{Q}$, Lu L, Niu X, Guo Y, Parino GR, Liu D. Nonmyeloablative allogeneic stem cell transplant in a patient with refractory systemic lupus erythematosus. Bone Marrow Transplant 2006; 37: 979-981.

201 Kötter I, Schmalzing M, Henes J, Vogel W, Kanz L. Current value of stem-cell transplantation in autoimmune diseases. Z Rheumatol 2008; 67: 716-722.

202 Lawitschka A, Peters C, Seidel MG, Havranek A, Heitger A, Fazekas $\mathrm{T}$ et al. Long-term remission in pediatric Wegener granulomatosis following allo-SCT after reducedintensity conditioning. Bone Marrow Transplant 2011; 46: 462-463.

203 Rizzo JD, Wingard JR, Tichelli A, Lee SJ, Van Lint MT, Burns LJ et al. Recommended screening and preventive practices for long-term survivors after hematopoietic cell transplantation: joint recommendations of the European Group for Blood and Marrow Transplantation, the Center for International Blood and Marrow Transplant Research, and the American Society of Blood and Marrow Transplantation. Biol Blood Marrow Transplant 2006; 12: 138-151.

204 Burt RK, Shah SJ, Dill K, Grant T, Gheorghiade M, Schroeder $\mathbf{J}$ et al. Autologous non-myeloablative haemopoietic stem-cell transplantation compared with pulse cyclophosphamide once per month for systemic sclerosis (ASSIST): an open-label, randomised phase 2 trial. Lancet 2011; 378: 498-506.

This work is licensed under the Creative Commons Attribution-NonCommercial-No Derivative Works 3.0 Unported License. To view a copy of this license, visit http://creativecommons.org/licenses/by-nc-nd/3.0/ 